\title{
Open-Field Magnetic Resonance Imaging: Diagnostic Procedures and Protocols in the Brain
}

\author{
W. W. ORRISON Jr.
}

Introduction 149

High-Contrast Versus High-Resolution MRI 150

Technical Factors 150

Fluid-Attenuated Inversion Recovery 152

Contrast Agents 153

Safety 154

Cranial Imaging 156

MR in Brain Disorders 156

Neoplasms 156

Infections 157

Vascular Disease 159

Head Trauma 161

Hemorrhage 162

White Matter Disease 164

Pituitary Imaging 166

Diagnostic Yield and Reader Experience 168

References 169

\section{- Introduction}

Magnetic resonance imaging (MRI) is currently performed with scanners operating at field strengths ranging from 0.02 to $4.0 \mathrm{~T}$ [1-5]. Multiple manufacturers now supply open design MRI systems that operate predominately at field strengths below $0.5 \mathrm{~T}$. Issues regarding field strength remain controversial and largely unresolved. This includes diagnostic yield, imaging sequences, manufacturer variation, diagnostic accuracy, adequacy of image quality, cost effectiveness, and safety [6-16]. In spite of these unresolved issues clinical MR units operating at $0.5 \mathrm{~T}$ or below may make up as much as $80 \%$ of the systems in use in developed countries, and more than 2000 of these lower field strength systems are operational in the United States. At least six manufacturers offer an array of clinical MR systems below $0.6 \mathrm{~T}$, with the sales of open design systems rapidly increasing. Brain imaging on high-field strength magnets in general provides higher resolution, but such systems are more costly to site, operate, and maintain. Open design low-field strength systems tend to demonstrate higher contrast with slightly less resolution; however, costs for siting, operation, and maintenance are significantly lower. In addition, patient tolerance is often superior to that seen in a high-field environment. Technical factors can be critical at both 
high and low field; however, lower field strength systems tend to be more heavily criticized [10].

\section{- High-Contrast Versus High-Resolution MRI}

As field strength changes in MR, there is a direct effect on relaxation times [17-19]. A shortening of $\mathrm{T} 1$ occurs as the field strength decreases,

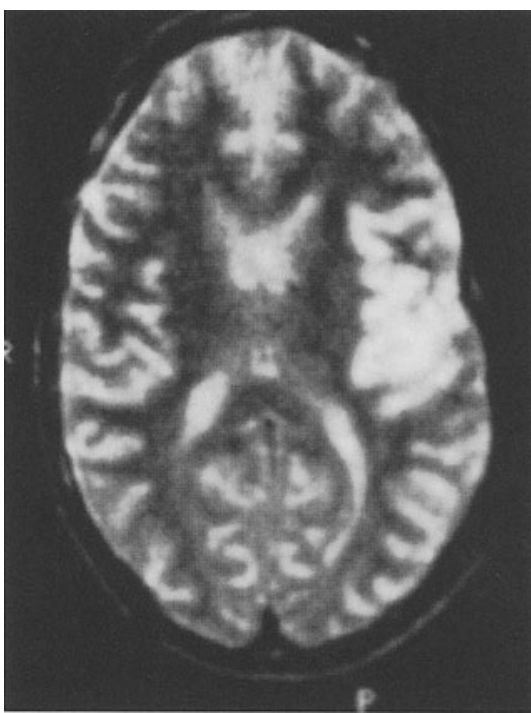

Fig. 1. T2-weighted open-design, low-field MRI demonstrat ing marked abnormal signal intensity in the left medial temporal lobe. High-field MR interpreted as normal. (Image from a $0.64-\mathrm{T}$ Toshiba open MR system)

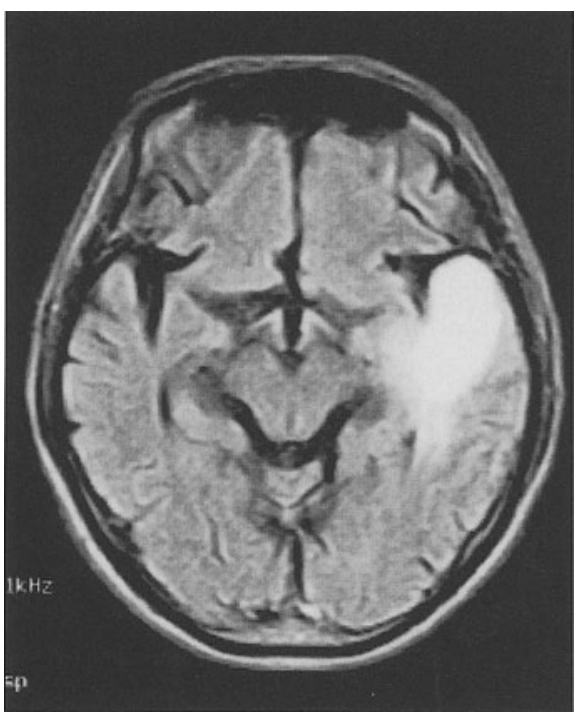

Fig. 2. FLAIR sequence (TR 5500, TE 104, TI 1550) demonstrating "black CSF" and abnormal hyperintensity in the left temporal lobe on this heavily $\mathrm{T} 2$-weighted sequence. (Image from a GE 0.2-T open-design magnet) and there is thus an improvement in signal-tonoise per unit time at lower fields. This results in improved lesion contrast [19].

When interpreting brain images at lower field strengths it is important to remember that as the field strength decreases, contrast increases. In general, a high-field-strength scanner provides higher resolution. This implies that if there is a detectable difference in tissue contrast, the higher-field-strength magnet demonstrates smaller regions of difference, and the images are clearer. However, when there is no difference in contrast, regardless of size, the lesion is not apparent. The use of MR contrast agents is based in part on this principle. When lesion contrast is not evident on routine MR and not enhanced by contrast, the lesion goes undetected. Since lower field strength improves contrast on MR, there is the possibility of detecting lesions with low-field MR that go undetected by either high-field MR or contrast-enhanced high-field MR. An example is the report of the longitudinal relaxation rate, $1 / \mathrm{T} 1$ values of mobile water protons at lower field strengths for distinguishing between pituitary tumor types [20]. Figure 1 also illustrates this point in a case of herpes simplex encephalitis detected by $\mathrm{T} 2$ imaging at low field $(0.06 \mathrm{~T})$ but undetected by $\mathrm{T} 2$ at $1.5 \mathrm{~T}$. Imaging sequences such as fluid-attenuated inversion recovery (FLAIR) may eliminate this low-field advantage in many cases (Fig. 2).

\section{- Technical Factors}

In brain imaging at lower field strengths the more open designed magnet frequently allows imaging of patients who are unable to tolerate the older "long-bore" design. Although "short-bore" systems are becoming more widely available, in all probability the most open design will continue to be preferred by many patients. The availability of an open magnet often dictates that the patient being scanned is either younger or more difficult. However, as a direct result of this open design these more difficult patients frequently require less sedation. It is common practice in open MRI to reserve sedation for only those patients who are unable to follow instructions, regardless of age. Successful imaging of children as young as 3 years of age has routinely been accomplished on open systems by having the parent or other family member accompany the patient in the scan room. This individual can stand or sit next to the patient, if necessary, and simply holding the patient's hand in some instances is sufficient to al- 
Table 1. Brain protocols supplied by manufacturers for T1 sagittal slice orientation

\begin{tabular}{|c|c|c|c|c|c|c|c|}
\hline & Fonar & GE & Hitachi & Picker & Siemens & Toshiba & Toshiba \\
\hline Field strength (T) & $0.35 \mathrm{~T}$ & $0.2 \mathrm{~T}$ & $0.3 \mathrm{~T}$ & $0.23 \mathrm{~T}$ & $0.2 \mathrm{~T}$ & $0.35 \mathrm{~T}$ & $0.064 \mathrm{~T}$ \\
\hline Scan time & $3: 56$ & $6: 34$ & $2: 52$ & $11: 31$ & $4: 12$ & $5: 22$ & $9: 00$ \\
\hline Repetition time & 600 & 483 & 550 & 30 & 588 & 500 & 68 \\
\hline Echo time TE1/TE2 & 30 & 26 & 25 & 10 & 15 & 20 & 24 \\
\hline Number of averages & 2 & 5 & 2 & 1 & 3 & 2 & 1 \\
\hline Field of view & 240 & $19 \times 19$ & 240 & 360 & $16 \times 22$ & $20 \times 20$ & 110 \\
\hline Number of slices & 11 & 7 & 11 & 120 & 19 & 8 & 32 \\
\hline Slice thickness (mm) & 5 & 3.0 & 5 & 1.5 & 5 & 3.0 & 4.5 \\
\hline Flip angle (degrees) & 90 & 90 & 90 & 35 & 90 & 90 & 45 \\
\hline Matrix hor/ver & $192 \times 256$ & $256 \times 160$ & $192 \times 192$ & $180 \times 256$ & $134 \times 256$ & $160 \times 256$ & $256 \times 256$ \\
\hline
\end{tabular}

Table 2. Brain protocols supplied by manufacturers for T2 axial slice orientation

\begin{tabular}{llllllll}
\hline & Fonar & GE & Hitachi & Picker & Siemens & Toshiba & Toshiba \\
\hline Field strength (T) & $0.35 \mathrm{~T}$ & $0.2 \mathrm{~T}$ & $0.3 \mathrm{~T}$ & $0.23 \mathrm{~T}$ & $0.2 \mathrm{~T}$ & $0.35 \mathrm{~T}$ & $0.064 \mathrm{~T}$ \\
Scan time (min) & $8: 54$ & $12: 28$ & $8: 06$ & $9: 48$ & $7: 22$ & $9: 41$ & $17: 00$ \\
Repetition time & 2700 & 3700 & 4100 & 3630 & 4284 & 3000 & 2000 \\
Echo time TE1/TE2 & 115 & 96 & 130 & 120 & 106 & 20 & 105 \\
Number of averages & 1 & 4 & 84 & 1 & 3 & 1 & 2 \\
Field of view & 240 & $24 \times 24$ & 240 & 300 & $19 \times 22$ & $20 \times 20$ & 110 \\
Number of slices & 17 & 22 & 16 & 23 & 19 & 12 & 14 \\
Slice thickness (mm) & 5 & 5 & 5 & 5 & 5 & 3 & 10 \\
Flip angle (degrees) & 90 & 90 & 90 & 100 & 90 & 90 & 90 \\
Matrix hor/ver & $192 \times 256$ & $256 \times 192$ & $224 \times 224$ & $162 \times 256$ & $170 \times 256$ & $192 \times 256$ & $256 \times 256$ \\
\hline
\end{tabular}

Table 3. Brain protocols supplied by manufacturers for FLAIR axial slice orientation

\begin{tabular}{llllll}
\hline & GE & Hitachi & Picker & Siemens & Toshiba \\
\hline Field strength (T) & $0.2 \mathrm{~T}$ & $0.3 \mathrm{~T}$ & $0.23 \mathrm{~T}$ & $0.2 \mathrm{~T}$ & $0.35 \mathrm{~T}$ \\
Scan time & $10: 06$ & $6: 24$ & $10: 42$ & $7: 19$ & $5: 46$ \\
Repetition time & 5500 & 8000 & 3961 & 6000 & 8000 \\
Echo time TE1/TE2 & 112 & 117 & 120 & 93 & 120 \\
Inversion time & 1550 & 1800 & 1600 & 1600 & 1900 \\
Number of averages & 2 & 87 & 1 & 2 & 2 \\
Field of view & $24 \times 24$ & 240 & 300 & $19 \times 22$ & $22 \times 22$ \\
Number of slices & 9 & 14 & 20 & 9 & 6 \\
Slice thickness (mm) & 8 & 5 & 7 & 5 & 90 \\
Flip angle (degrees) & 90 & $192 \times 192$ & $162 \times 256$ & $168 \times 256$ & $224 \times 256$ \\
Matrix hor/ver & $256 \times 128$ & & & & \\
\hline
\end{tabular}

low for satisfactory completion of the scan. It is also possible to keep younger children quiet in the magnet for extended periods of time by having a parent or sibling actually lie next to the child in the scanner. This can also serve as an effective adjunct to sedation for children who are reluctant to cooperate even when having received a full dose of sedative.

In general, imaging of the brain involves the use of T1-, T2-, and intermediate-weighted sequences. Image quality can be significantly enhanced for the $\mathrm{T} 1$ weighted sequences by using a gradient echo technique rather than a spin echo sequence. As with all gradient echo sequences, motion can be a significant degrading factor in image quality, and if patient motion is severe, a spin echo sequence can be substituted. At field strengths in the range of $0.06 \mathrm{~T}$ a typical gradient echo sequence can be substituted. At field strengths in the range of $0.06 \mathrm{~T}$ a typical gradient echo sequence would include a TR of 68 , TE of 24 , and FA of 60 or a similar configuration for adequate image quality. At $0.23 \mathrm{~T}$ excellent image quality can be obtained on an open MR system using TR of 30, TE of 10, and FA of 35 . A detailed summary of manufacturer supplied brain protocols successfully used in open systems of varying field strengths is included in Tables 1-3.

As with high-field imaging, standard $\mathrm{T} 2$ and proton density (intermediate) weighted sequences are usually obtained on lower field strength imaging systems. The value of these techniques in imaging of the brain is well established, and for a rapid screen T2-weighted sequences may be suffi- 


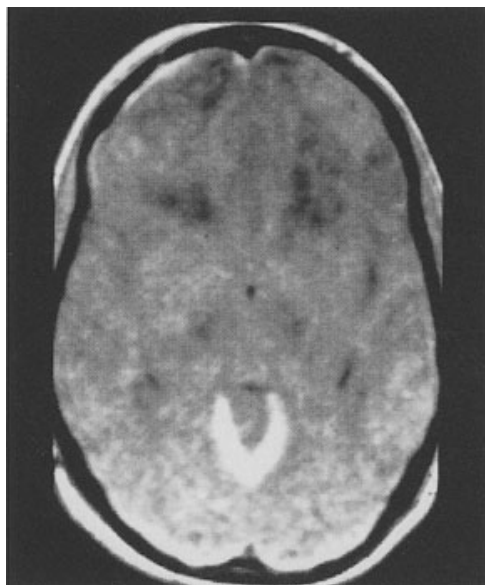

Fig. 3. T1 (TR 68, TE 24, FA 60) open-design, low-field MRI examination demonstrating acute SAH as markedly high signal intensity. (Image obtained on a 0.64-T Toshiba open MR system)

cient to exclude significant pathology. However, an additional advantage of lower field strength systems is the ability to detect changes that may go undetected at higher field (see Fig. 1, above). Another example is in the area of acute subarachnoid hemorrhage (SAH) where T1-, T2-, and proton density weighted imaging may be negative at high field but obvious on T1 weighted low-field images (Fig. 3). Therefore in general it is advantageous to perform at least both $\mathrm{T} 1$ - and $\mathrm{T} 2$ weighted sequences on all patients referred for a brain evaluation.

\section{Fluid-Attenuated Inversion Recovery}

The advent of fluid-attenuated inversion recovery (FLAIR) imaging has drastically altered the evaluation of the brain by $\mathrm{MR}$, and has given the brain imager yet another advantage in the diagnosis of cerebral pathology. FLAIR sequences produce heavily T2-weighted and cerebrospinal fluid (CSF) nulled images of the brain on MR. This novel method of imaging was first described by the group from Hammersmith Hospital in the United Kingdom and demonstrates dramatic changes on MRI that may otherwise go undetected $[1-3,8,21]$. By reducing the signal from CSF and enhancing the T2 weighting FLAIR sequences provide a unique opportunity to evaluate brain pathology (see Fig. 2). Clinical applications of FLAIR have been demonstrated in disease processes including $\mathrm{SAH}$, cerebral infarction, brain trauma, cerebral neoplasms, inflammatory conditions, and most notably demyelinating diseases $[1,5-7,21]$.

The routine use of FLAIR is recommended for all brain evaluations regardless of field strength, but, again, lower field strength scanners may prove to be advantageous in this regard. Higher field strength systems tend to demonstrate significant and often severe artifacts on FLAIR sequences. The artifacts that result from CSF or vascular flow and pulsation on high-field FLAIR images are less of a problem at lower field, and in some cases at low field can be virtually eliminated (Fig. 4).

One of the most significant limitations of FLAIR imaging has been the presence of signifi-
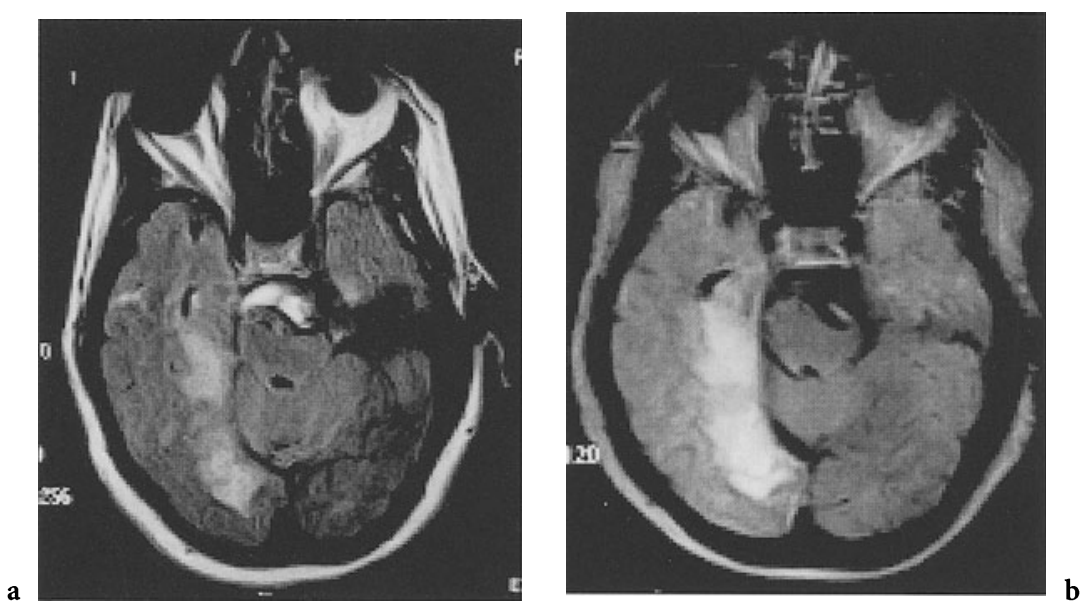

Fig. 4. a A 1.5-T FLAIR image (TR 8243, TE 112, T1 1600) demonstrating a right posterior cerebral artery infarction. Note the artifact in the prepontine cistern identified as high signal. (Image from a 0.23-T Picker open MR system) b A 0.23 -T FLAIR image (TR 4752, TE 120, TI 1600) de- monstrating the right posterior artery infarction seen in a but without the prepontine flow artifact that is prominent on high-field MR. (Image from a 0.23 -T Picker open MR system) 
cant artifacts that are particularly related to CSF motion. These are often encountered in the region of the lateral ventricles, foramen of Monroe, third ventricle, cerebral aqueduct, and fourth ventricle. These artifacts at high-field can be particularly problematic when attempting to evaluate cerebral pathology adjacent to regions of the brain that are contiguous with or adjacent to pulsatile CSF. One of the advantages of open MRI scanning at lower field strengths is a notable absence of these artifacts (see Figs. 4, 13).

\section{- Contrast Agents}

Contrast agents improve the diagnostic power of MR in several ways. Both the conspicuity of abnormalities and better demarcation of their borders are achieved through the use of MR contrast agents. The viable areas of neoplasms may be distinguished from surrounding edema in some cases and contrast also helps to date abnormalities, specifically with regards to cerebral infarctions.

The ideal contrast agent must be both effective and safe. The main objective of contrast agents in imaging is to enhance image contrast to render normal and pathological anatomy more conspicuous. Great advances have been made toward both of these ends, and while some drawbacks exist, research and development of new and improved contrast agents persists. Generally there is little difference between the use of contrast agents in children and in adults, the main difference being one of dose, based on weight and age. Children also tend to have a lower incidence of adverse reaction than adults, whether mild or severe, to all contrast agents [22].

Contrast agents are administered to patients in liquid form and function within the bloodstream or CSF. Accordingly the inherent properties of density, viscosity, and osmolality effect their safety and efficacy [23].

The United States Food and Drug Administration has approved three MRI contrast agents for intravenous administration: Magnevist (gadopentetate dimeglumine injection, Berlex Laboratories), Omniscan (gadodiamide injection, Nycomed), and ProHance (gadoteridol injection, Bracco Diagnostics). Since the element gadolinium is the base of all of these contrast agents, they all have similar mechanisms of action, biodistribution, and half-lives [24-27]. While these agents appear to have remarkably similar effectiveness and safety profiles, some differences do exist.

There are osmolality differences between Magnevist (1960 mmol/kg of water) [28], Omniscan
(789 mmol/kg water), and ProHance $(630 \mathrm{mmol} /$ $\mathrm{kg}$ water). The significance of this osmolality difference, however, is proportionally decreased by the administered volume of these agents being typically quite small.

Gadolinium is not normally present in a mammalian system except in trace amounts and has no known natural functions. It is highly toxic in its ionic form to humans, even at low doses. The contrast agents used for MR enhancement in the United States are gadolinium chelates that localize in the extracellular fluid compartment to be then rapidly excreted by the kidney. As the gadolinium ion is toxic, it must be complexed with ligands.

For all of these agents, the adverse reaction rate seems to be less than $4 \%[25,29-42]$. The adverse reactions that are most commonly experienced seem to be nausea, emesis, hives, headache, and local injection site reactions, such as irritation or a burning or cool sensation. The incidence of the anaphylactoid reactions that have been reported with all three of these FDA-approved intravenous MR contrast agents is so exceedingly rare that it is difficult to attempt to place any significance on these rates. At worst, the rate of this extreme sort of reaction from any of these agents is probably in the 1:100,000 range, and this may be as high as 1:450,000.

The use of Magnevist has been associated with transient elevations in serum bilirubin $(3 \%-4 \%$ of patients) that seems to spontaneously reverse within 24-48 h [31, 43]. The use of ProHance has not resulted in reports of such alterations in blood chemistry. All MRI contrast agents have been associated with delayed reactions of hypertension, vasovagal responses, and syncope. There are no known contraindications for Magnevist, Omniscan, or ProHance.

The administration of MRI contrast agents during pregnancy and lactation has not been determined to be without risk. To date no clinical trials have been reported on pregnant women. The studies performed on animals, however, using doses much higher than those employed clinically have produced a number of severe adverse effects on the fetus. Gadopentetate dimeglumine does cross the placenta and has been found in the fetal bladder [44]. The rate of clearance of MRI contrast agents from the amniotic fluid cycle has not been assessed. Until more data become available, routine administration of any of the MRI contrast agents in pregnant patients should not occur, unless the potential benefit justifies the risk to the fetus. It is also recommended that mothers refrain from breast feeding, while continuing to express milk, for $24 \mathrm{~h}$ following gadopentetate administration. 


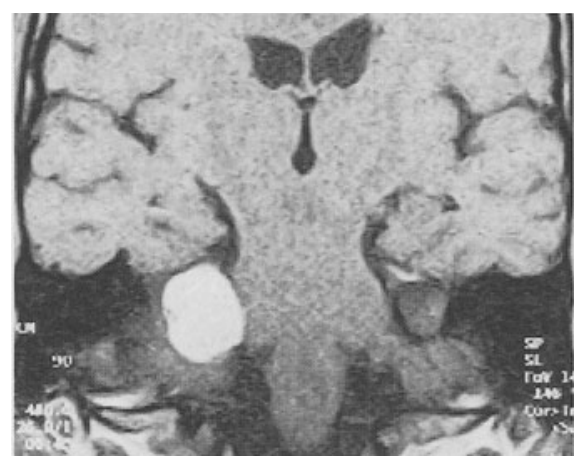

Fig. 5. Postcontrast MR (TR 480, TE 26) demonstrating enhancing right-sided acoustic neuroma from a Siemens 0.2 T open MR system. (Mark Leszczynski, RT, Memorial Open MRI, Houston, Texas, used with permission)

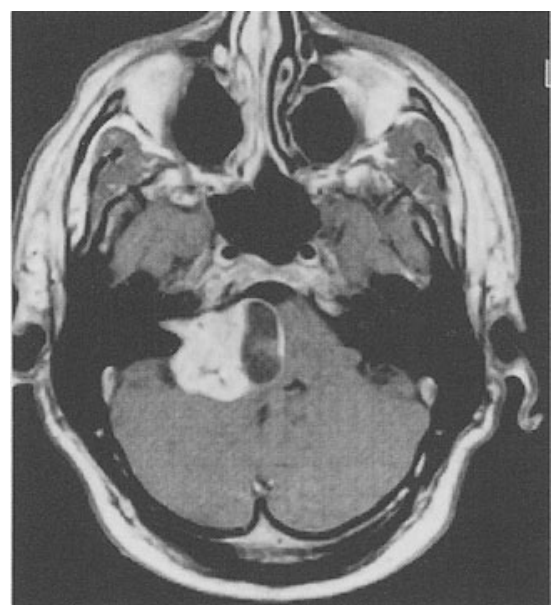

Fig. 6. Postcontrast T1 image (TR 650, TE 25) of an extraaxial acoustic neuroma. (Image from a 0.3-T Hitachi open MR system)

Our clinical experience with gadolinium imaging on low-field open-MRI has resulted in the use of a T1-weighted gradient echo technique with a bolus of one half of a $0.1 \mathrm{mmol} / \mathrm{kg}$ dose of gadolinium DTPA, with drip infusion of the remaining one-half dose diluted in $50 \mathrm{cc}$ sterile water [45]. Due to the longer scan times required at lower fields, the drip infusion technique provides optimum levels of gadopentetate dimeglumine at the actual times of image acquisition. Some low-field centers report using approximately 0.15$0.2 \mathrm{mmol} / \mathrm{kg}$ single injections with similarly improved results. The use of open low-field or $1.5-\mathrm{T}$ bore-type MR appears comparable, in our experience, for cranial central nervous system disease with or without contrast (Figs. 5, 6, 9, 25).

In general, the indications for the use of contrast in the brain are similar for high- and lowfield strength systems. The advantage of the open-design magnets in this regard is the ease of access to the patient for contrast administration and management. It is possible to perform rapid scan sequences on most open design systems, and the role of dynamic sequences in addition to those described in the subsequent section on pituitary imaging remains to be fully established. It is conceivable that dynamic perfusion studies with MR contrast will be an important part of the management of patients with cerebral vascular disease in the future.

\section{Safety}

Recent reports and at least one survey of MR facilities show potential areas of significant concern regarding safety, with a number of accidents and death associated with MR having been reported [46-50].

Numerous studies have been performed to investigate the potential bioeffects of MRI. The majority of these studies support the widely held view that no significant biological health risks are associated with the use of this modality. The effects on humans and biological systems of strong static magnetic fields are not well understood.

Some of the literature does include data that appear to be contradictory; however, no evidence has demonstrated conclusively any irreversible or hazardous biological effects related to humans being exposed to acute, short-term static mag-

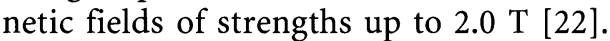

Certain devices must be precluded from entering the magnet room, for reasons of them being mechanically attracted by the field of the magnet or having their function altered by the presence of the fields. The FDA requires labeling of MR systems to indicate that the device is contraindicated for patients who have implants such as internal cardiac pacemakers, implantable cardiac defibrillators, cochlear implants, neurostimulators, bone-growth stimulators, implantable electronic drug infusion pumps, and similar devices, since electromagnetic fields produced by the MR system may seriously interfere with the operation of these devices [51].

Our three 1.5-T sites have had at least four documented incidences of ferromagnetic objects unintentionally entering the magnetic field and being drawn into the magnet. In one of these instances there was minimal injury when during equipment repair, a repairman and his equipment were drawn into the magnet. In a second instance, a significant injury could have occurred if a patient had been present in the magnet when a 
metallic writing pen was pulled from a radiologist's pocket as he entered the magnet room. There have been two instances of minor burns related to metallic objects touching the patient during the scan. We have experienced none of these adverse effects in 10 years of open design magnet use at lower field strengths.

Concern for injury from internal or external metallic objects is minimal or nonexistent at very low-field strengths. MR facilities report accidents primarily involving static ferromagnetic objects that became projectiles when subjected to the pull of the magnetic field. Additional injuries have been encountered from MR accessories causing burns [46-50]. A potential injury includes the effect of high magnetic fields that are in general considered safe, but this is unproven. There is a more immediate danger of injury from damage to devices such as implanted pacemakers [47]. An additional problem is that MR accidents are probably grossly underreported [46-50]. Measurements of magnetic forces and torques at $0.064 \mathrm{~T}$ support the added safety for patients from both internal and external metal objects when being scanned in open design low-field systems [52].

At higher field strengths several safety concerns exist for scanning patients who have certain ferromagnetic implants, materials, or foreign bodies. Primarily this is because of the possibility of movement or dislodgment of these objects [5355]. The possibility exists also of current induction, excessive heating, and the misinterpretation as an abnormality of an artifact produced by such an object [53,55-59]. Several considerations must be taken into account before allowing a patient who has a ferromagnetic object to be scanned, including (a) the strength of the magnetic field to which the patient is exposed, (b) the degree of ferromagnetism manifest by an object, (c) the mass and geometry of the object and its location and orientation in a patient, and (d) the length of time the object has been in place.

For patients who present to the MRI with a history of metallic foreign bodies such as shrapnel, bullets, slivers, or other types of metallic fragments the risk depends on several factors. A patient encountering the static magnetic field of an MR system with an intraocular metallic foreign body, for example, is at significant risk for a serious eye injury. One patient was blinded at the completion of his MR examination on the way out of the MR imager [60]. A patient undergoing an MR examination at one scanner has absolutely no assurance that it is necessarily safe to undergo another MR scan at the same or another location. It has been established that the use of plain film radiography may be an acceptable technique for identifying or excluding an intraocular metallic foreign body that represents a hazard [61].

The hazard of open-design 0.064-T MR regarding intraocular ferromagnetic metal fragments has been evaluated using both in vitro and in vivo animal experiments [62]. An important observation during these experiments was the fact that all motion was increased by increasing the speed at which fragments entered or exited the magnetic field. Regardless of field strength, the forces acting on metallic fragments, and the subsequent risk to patients, can be effectively reduced by decreasing the speed of entry into and the exit from a magnetic field. In other words, regardless of field strength, simply moving the patient in and out of the scan field slowly significantly reduces patient risk.

At least two dozen patients with cardiac pacemakers have been placed in MRI systems, either intentionally or inadvertently. The documentation is such that at least five of these individuals have died, although it should be stressed that the cause of death in these patients is unknown. A study demonstrating total pacemaker inhibition [63] and pacemaker malfunction in another [64] has serious safety implications for studying patients who have pacemakers being imaged. It is commonly understood that scanning any patient who has a cardiac pacemaker is contraindicated.

No standardized testing criteria exist by which MR compatibility claims may be assessed $[65,66]$. Not even the term "MR compatible" is defined. No standardization exists that ensures that in such devices as implanted intracranial aneurysm clips, for example, that clips produced from one run are identical in ferromagnetic properties to those of another. This explains why some researchers find some clips "MR compatible" and others find the same clip types respond to the presence of a strong magnetic field. At this point several physicians have decided not to scan any patient with an intracranial aneurysm clip in place until firm guidelines are established [22]. If MR scanning is deemed imperative, the lower field open design magnet may offer less risk than the traditional 1.5-T bore-type systems.

The sensations of claustrophobia and a variety of other unpleasant psychological reactions including anxiety and panic are encountered by as many as $5 \%-10 \%$ of patients during or precipitating MRI. The originating factors include the narrow dimensions of the interior of the bore-type of scanner; the length of the examination; the banging, gradient-induced noises; the encompassing and dark conditions within the traditional bore of 
the scanner, and other factors [67-75]. Offering an open design magnet is probably the most effective solution to these problems.

\section{- Cranial Imaging}

\section{MR in Brain Disorders}

Virtually every type of brain pathology is responded to clinically through the utilization of MR. Since treatment may be dramatically altered, the value of a normal MR scan is not to be underestimated [76]. The decrease in clinic visits, patient concern, and physicians' and other health care professionals' time are relevant in terms of financial and psychological relief [77]. It could be said that the normal brain MR might be one of the most cost-effective studies in all medicine.

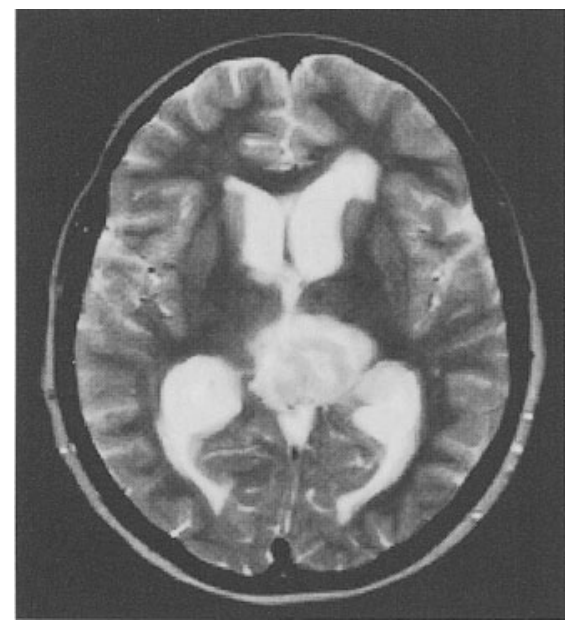

Fig. 7. T2-weighted image (TR 3900, TE 120) of a highgrade glioma. (Image from a $0.3-\mathrm{T}$ Hitachi open MR system)
Considering this is one of the most expensive areas of the health care system, it is certainly warranted to try to exit the patient from this costly system, as well as relieve them of the high stakes that accompany brain disorders [76]. Neoplasms, infections, cerebrovascular disease, head trauma, intracranial hemorrhage, and white matter disease are several disease categories for which the use of MR has proved essential [77].

\section{Neoplasms}

Obviously much more attention is given to the abnormal than the normal brain MRI. New primary brain tumors are identified in approximately 40,000 patients in the United States each year, which may result in paralysis, dementia, seizures, and death [77]. Mass effect, edema, hemorrhage, and contrast enhancement are the recognizable characteristics of a neoplasm on MR. Because of the nature of the brain, the classifications of benign or malignant pathology may not apply, as the most "benign" of tumors can be devastating if located in a critical part of the brain [76]. Until recently the location of an intracranial neoplasm was more telling than the cell type of the neoplasm. Even if considered histologically "benign," many intracranial neoplasms are thought to "behave" in a malignant manner.

The availability of functional brain imaging [77] has changed the traditional approach to intracranial masses including neoplasms. Malignant neoplasms once thought to be unresectable because of their close anatomic relationship to vital areas of brain function are now being successfully resected without resulting loss of function. This is due to the location not being as closely related to "vital" brain regions as would be anticipated from
Fig. 8. T1 (TR 68, TE 24, FA 60) opendesign, low-field MRI demonstrating ring enhancing mass from metastatic disease following administration of gadolinium. (Image from a 0.64-T Toshiba open MR system)

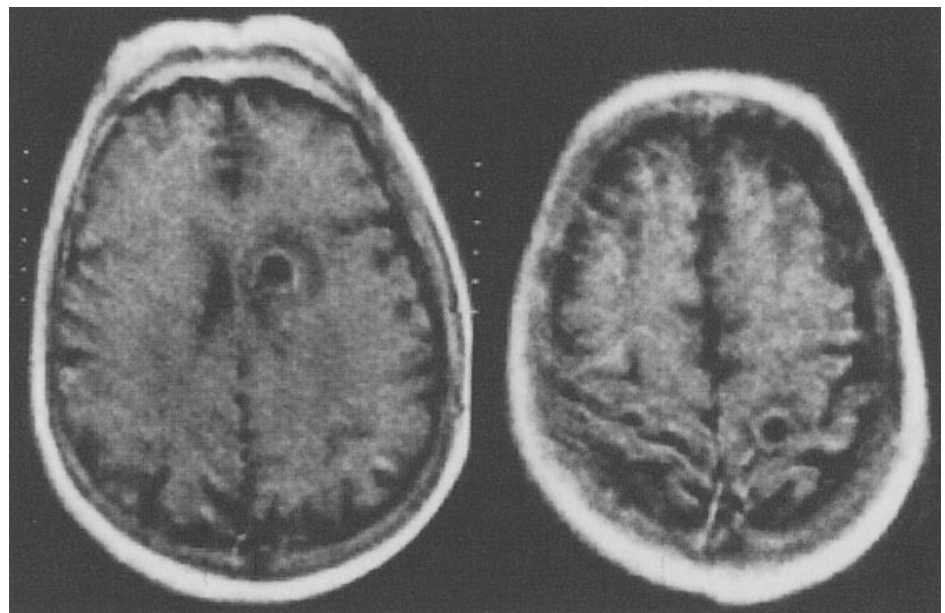


traditional predictions. The number of neoplasms that can be effectively treated is increasing, even though many continue to be refractory to treatment. Although most functional magnetic resonance imaging (fMRI) is currently limited to high-field bore types of systems, fMRI has been performed successfully on lower field strength magnets. The role of fMRI on open design lowfield systems remains to be defined.

The two most important criteria for evaluation of images of intracranial neoplasms are age of the patient and location of the mass [77, 78]. On MR brain tumors are often described as being intraaxial, within the brain substance, or extra-axial, outside the brain substance. Benign tumors are frequently extra-axial and easier to resect surgically (Fig. 6). Most often intra-axial, malignant tumors frequently extend far into the brain beyond the appearance on MR (Fig. 7). Surgical cure is difficult, recurrence common, and these tumors include metastatic cancer from other organ systems [76].

Most commonly arising from primary neoplasms of the lung and breast, metastatic cancer represents approximately $25 \%$ of all brain tumors (Fig. 8). Metastatic brain tumors may also arise from the gastrointestinal tract, the genitourinary tract, and melanoma [76].

\section{Infections}

Infection of the brain is becoming one of the more common indications for brain imaging and may be the result of extension of infectious conditions in the sinuses, ear, orbit, or superficial soft tissues. The bloodstream can carry the infection from various parts of the body. Many of these conditions respond rapidly to treatment which make these some of the most urgent and important scans performed. Early treatment of brain infection may mean the difference between the patient recovering, being severely incapacitated, or dying [76] (Fig. 9).

Often congenital central nervous system (CNS) infections are caused by what is referred to as the TORCH agents: toxoplasmosis, rubella, cytomegalovirus, and herpes simplex virus. Other important causes of congenital CNS infections are human immunodeficiency virus (HIV) and syphilis [79].

The most common form of CNS infection is meningitis [80]. This condition can be divided into three general categories: acute pyogenic meningitis (most often bacterial infections), lymphocytic meningitis (usually viral), and chronic meningitis (examples are tuberculosis and coccidioidomycosis).

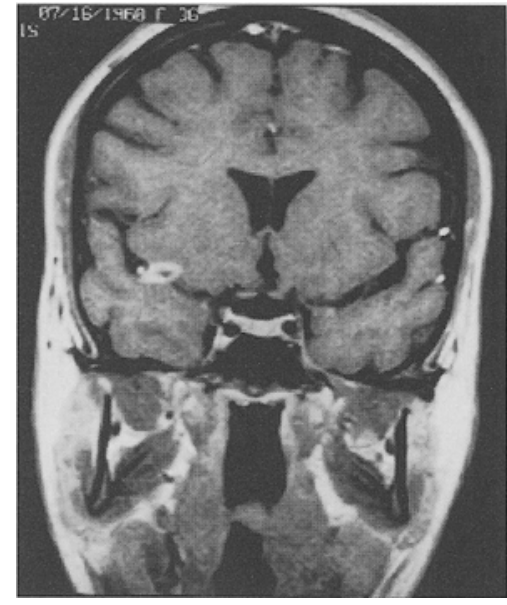

Fig. 9. Postcontrast enhanced MR (TR 500, TE 25) demonstrating a ring enhancing inflammatory lesion. (Image from a 0.3-T Hitachi open MR system)

In the evaluation of patients with suspected meningitis, MRI is superior to computed tomography (CT) [22]. Precontrast T1-weighted images may demonstrate obliterated cisterns that enhance strongly following contrast administration. In severe cases extension of enhancing subarachnoid exudate deep into the sulci can be seen.

Meningitis is conspicuous on postcontrast T1weighted images; however, unenhanced MR images often do not detect active meningeal inflammation [82, 83]. In chronic meningitis contrast-enhanced T1-weighted MR scans reveal the characteristic basal meningeal inflammatory pattern seen on contrast-enhanced CT studies [84].

The earliest stage of purulent brain infection is cerebritis [80]. This diffuse infection often leads to abscess formation with characteristic neuroimaging features [85]. The organisms most frequently isolated from cerebral abscesses are streptococci, including both aerobic and anaerobic, and staphylococci. Gram-negative organisms, however, are an increasing cause of cerebral abscess [86].

In MR the findings in brain abscess vary with time. An ill-defined subcortical hyperintense zone can be noted on T2-weighted images during the initial, early cerebritis stage. In postcontrast $\mathrm{T} 1$ weighted studies poorly delineated enhancing areas within the isointense to mildly hypointense edematous region may be disclosed.

The central necrotic area is typically hyperintense to brain on proton-density and $\mathrm{T} 2$-weighted sequences during the late cerebritis stage. On T1weighted images the thick, somewhat irregularly marginated rim appears isointense to mildly hyperintense and isointense to relatively hypointense 
Fig. 10. T1 (TR 68, TE 24, FA 60) open-design, lowfield MRI demonstrating rim enhancement in a cerebral abscess following gadolinium administration. (Image from a 0.64-T Toshiba open MR system)

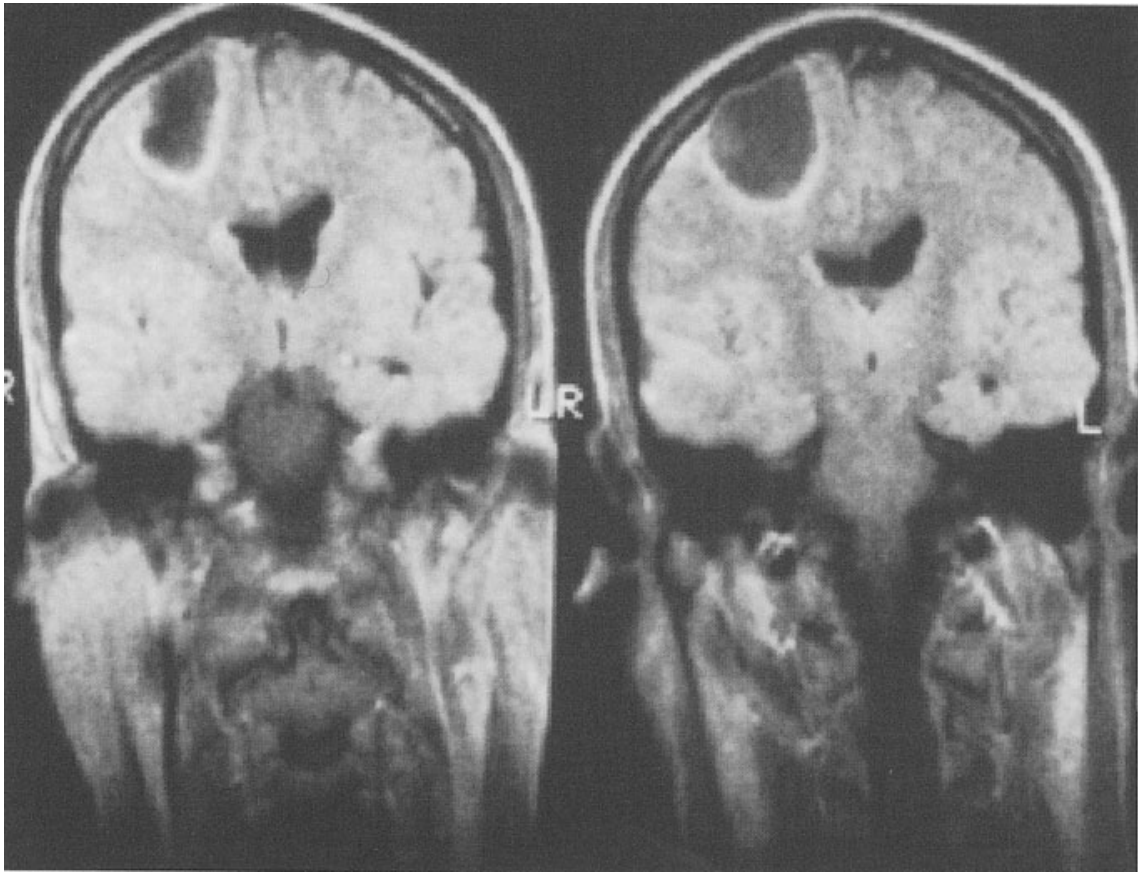

on proton density and T2-weighted scans. In nearly all cases peripheral edema is present. Following contrast administration the rim enhances intensely (Fig. 10). Satellite lesions are commonly present [87]. The collagenous abscess capsule is visible on unenhanced scans, during the early and late capsule stages, as a comparatively thinwalled, well-delineated isointense to slightly hyperintense ring that becomes hypointense on T2weighted sequences.

While encephalitis is usually viral, it may be caused by a broad spectrum of agents. In the United States and Europe this diffuse, nonfocal brain parenchymal inflammatory disease is most commonly caused by herpes simplex encephalitis.

The typical early findings of MR include gyral edema on T1-weighted images and high signal intensity in the temporal lobe or cingulate gyrus on T2-weighted scans. Often the signal abnormalities extend into the insular cortex and spare the putamen. In the early stages enhancement following contrast administration is unusual [88]. While petechial hemorrhages occur, they are uncommonly identified early in the disease process. As previously demonstrated, open low-field MR may be advantageous in the early diagnosis of this and other progressive brain disorders (see Fig. 1).

Fungi are single-celled organisms that are very different from bacteria in size, structural complexity, chemical composition, and their pathological effects on the central nervous system [89]. Imaging findings vary depending on the specific fungus involved. Gelatinous-appearing pseudocysts are produced by cryptococcus, and these extend along enlarged perivascular spaces, particularly in the basal ganglia. Imaging of aspergillosis usually shows that of multifocal hemorrhagic mycetomas or penetrating or large vessel cerebral infarcts, since this is an angioinvasive fungus. In CNS coccidioidomycosis, what is usually seen is meningeal inflammation with infectious purulent and caseous granulomas. Communicating hydrocephalus is common, and the basal meninges may appear notably thickened [90].

CNS infections can be caused by several different parasites and include toxoplasmosis, cysticercosis, schistosomiasis, sparganosis, amebiases, and echinococcosis. Imaging findings are related to the stage of the infection at presentation [92]. On imaging studies obtained during the vesicular stage of parenchymal cysticercosis, the larva appears as a round CSF-like cyst with a mural nodule that represents its scolex (head). Edema and cyst wall enhancement occur on imaging studies during the colloidal vesicular stage. In the granular nodular stage, the residual cyst is typically isointense compared to brain on unenhanced T1weighted images and isointense to hypointense on T2-weighted sequences. By the final, nodular calcified stage, the granulomatous lesion has contracted to a fraction of its initial size and is completely mineralized [91].

Imaging findings of miscellaneous parasitic infections vary with the disease stage, although 
multiple conglomerate, ring-enhancing lesions with striking peripheral edema are typical [92]. In sparganosis, imaging findings are not distinguishable from other granulomas or neoplastic masses [93]. In echinococcosis, also known as hydatid disease, the imaging findings are striking. What is typical is a single, thin-walled spherical CSF-density cyst in the parietal area [92]. Rarely multilocular or multiple lesions occur.

\section{Vascular Disease}

The third leading cause of death in the United States is cerebrovascular disease, most of which affects individuals over the age of 55, and is related to atherosclerotic disease. Patients presenting for MR with cerebrovascular disorders commonly suffer from one of three conditions: (a) a transient ischemic attack (TIA), a neurological deficit that clears in less than $24 \mathrm{~h}$, (b) a reversible ischemic neurological deficit (RIND), in which the neurological deficit lasts longer than $24 \mathrm{~h}$ but clears, or (c) cerebrovascular accident (CVA), or completed stroke, in which the patient does not recover all lost neurological function. A "stroke in progress" is a fourth condition for which MR (and particularly MRA) may be used. This medical emergency is now often treated in a manner similar to a heart attack. Every second counts in this circumstance. It has been possible to entirely reverse strokes that would have otherwise left the patient paralyzed [76].

With standard spin-echo MRI arterial patency may be difficult to assess. Vessel occlusion with intraluminal thrombus is usually present when intraluminal signal that is isointense with brain on long TR/short TE or long TR/long TE is observed [94]. In-flow phenomena, however, as well as slow or in-plane flow in tortuous, ectatic vessels can mimic intraluminal thrombi. The presence of a normal "flow void" does not exclude significant extracranial carotid stenosis [94, 95].

Diminished blood flow to all parts (global) or selected areas (regional or focal) of the brain is referred to as cerebral ischemia [96]. Stroke is a dynamic process that changes over time, involving the location and degree of cerebral ischemia and resulting infarction. The parameters of flow decrement, location, duration, and tissue volume involved [96] are predicated by ischemic manifestations. Progressing in stages, a stroke moves from ischemia to actual infarction [97].

The lay term "stroke" encompasses a heterogeneous group of widely differing cerebrovascular disorders. Four major types include cerebral infarction, primary intracerebral hemorrhage
(ICH), SAH, and venous occlusions. In cerebral ischemia the imaging findings vary significantly over time. More often acute infarcts are identified and localized on MR compared to CT scans (see Fig. 4) [98]. Open low-field imaging may prove particularly helpful in the management of these patients who often require extensive life support assistance. In addition, areas of ischemia can often be detected within minutes of the acute event. On standard spin-echo MR scans obtained within $24 \mathrm{~h}$ of the ictus, $80 \%$ of acute infarcts are visible [99]. On MR the earliest findings are vascular flow-related abnormalities, including absence of normal flow void and slow flow with intravascular arterial enhancement [100]. Within minutes of symptom onset, these signs are detectable [101, 102]. In nearly three-quarters of acute cortical infarcts, intravascular enhancement is seen [101].

Early on, T1-weighted images also manifest morphological changes, particularly brain swelling. Such anatomic changes may precede the development of increased signal on proton density or T2-weighted sequences. While usually not observed before $8 \mathrm{~h}$ on high-field, T2 hyperintensity does occur (Fig. 11). These changes may be detected within the first hour on lower field strength open-design MR systems where tissue contrast is greater. In about one-third of cases abnormal meningeal enhancement is seen adjacent to cortical infarcts that are aged 1-3 days [101]. In $10 \%-20 \%$ of patients standard high-field MRI sequences fail to detect acute stroke [103].

As mentioned above, because cerebral infarction is a dynamic process, its imaging manifesta-

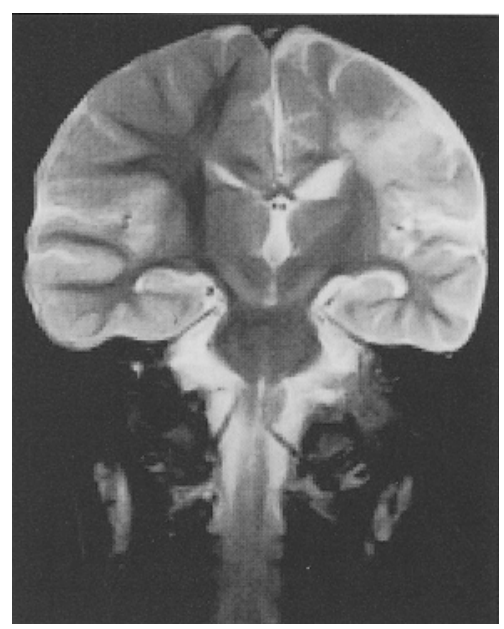

Fig. 11. T2 image (TR 4000, TE 48) in cerebral infarction. Note the cortical and subcortical increased signal intensity of the left hemisphere. (Images from a 0.2-T Siemens MR system. Margareta Arens, MD, St. Barbara Klinik, Hessen, Germany, used with permission) 


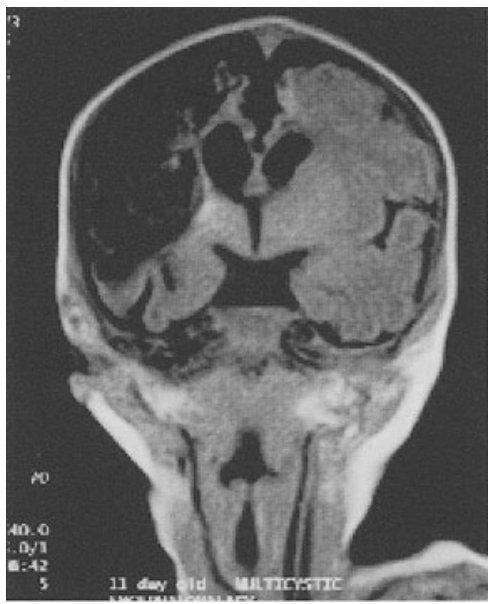

Fig. 12. A T1-weighted image (TR 540, TE 15) of encephalomalacia from a Siemens 0.2-T MR system. (Margareta Arens, MD, St. Barbara Klinik, Hessen, Germany, used with permission)

tions continue to evolve with time. Within 2-4 days after ictus the two earliest signs of acute infarction of intravascular and meningeal enhancement begin to diminish [101]. The parenchymal contrast enhancement that ensues can persist for weeks. Becoming more prominent, edema appears hypointense to cortex on T1-weighted images and hyperintense on T2-weighted images. Mass effect increases and then gradually diminishes.

A noticeable decrease in signal intensity is sometimes observed on T2-weighted images during the second post-ictal week. The initially highsignal changes may largely regress or even disappear. It is likely that this "fogging" effect is due to a reduction in edema and leakage of proteins from cell lysis [104, 105].

The end result of the destructive process of prolonged ischemia is chronic infarction. The pathological hallmarks of stroke residua are volume loss and gliosis, both reflected in gross specimens of chronic infarcts. On MR focal well-delineated low-attenuation or encephalomalacic areas are seen in the affected vascular distribution. The loss of cerebral tissue volume is reflected in the prominence of the adjacent sulci and the enlargement of the ipsilateral ventricle (Fig. 12). After 810 weeks the enhancement disappears. Rarely dystrophic calcification may occur in the infarcted brain [106].

Since relaxation times are prolonged in both, the MR differentiation of subacute from chronic ( $<2$ weeks) infarction on standard spin-echo sequences may be difficult because relaxation times are prolonged in both [107]. Mass effect and contrast enhancement are absent in old infarcts $(>8-$ 10 weeks). Ipsilateral brain stem atrophy and hyperintensity on T2 or FLAIR imaging may result from wallerian degeneration of axons and their myelin sheaths [108] (Fig. 13). Gyriform signal changes can sometimes be identified on T1weighted images if cortical hemorrhage or secondary calcification has occurred. These are either hypo- or hyperintense depending on the age of the hemorrhage. Old infarcts reveal ribbonlike very hypointense foci on T2-weighted images [109].

Lacunar infarcts, which account for $15 \%-25 \%$ of all strokes [110], are seen as rounded or slitlike lesions on MR that are hypointense to brain on
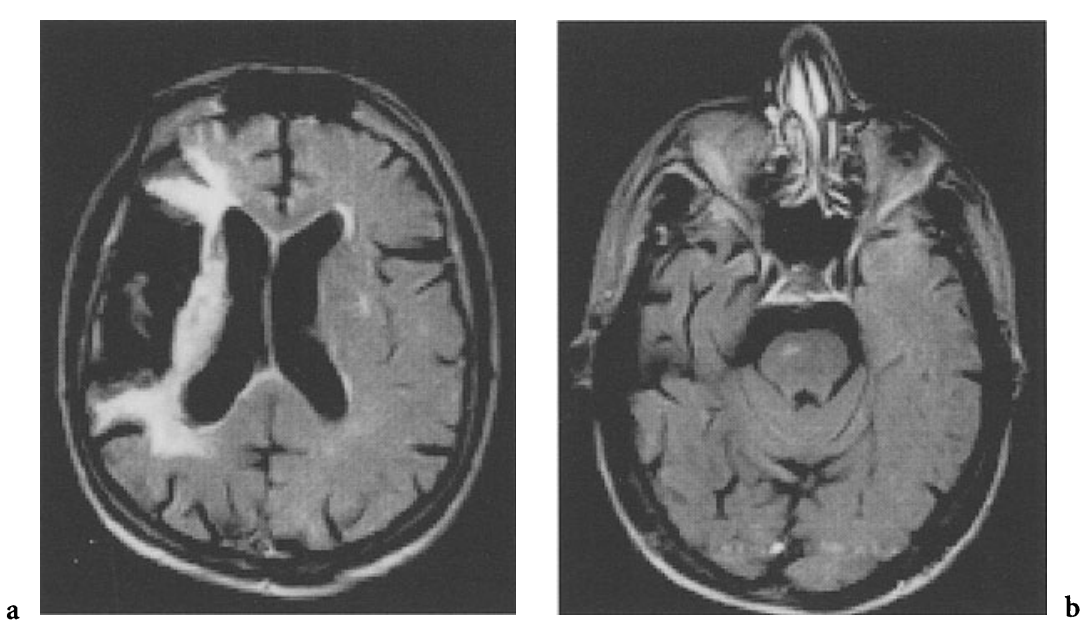

Fig. 13. a FLAIR image (TR 4750, TE 120 , TI 1600) demonstrating a right middle cerebral artery infarction. (Image from 0.23-T Picker open MR system.) b FLAIR image (TR 4750 , TE 120 , TI 1600) demonstrating wallerian degenera- tion associated with the right middle cerebral artery infarction in a. Note the abnormal increased signal intensity in the right pons and the absence of artifacts (compare to Fig. 4 a). (Image from a 0.23 T Picker open MR system) 
T1-weighted images. On T2-weighted sequences well-delineated hyperintense areas are identified. Following contrast administration, some late acute or early subacute lacunar infarcts may enhance [110].

Hypoxic-ischemic encephalopathy (HIE) results from global rather than focal brain injury (see Fig. 12). Common causes of HIE are severe prolonged hypotension, cardiac arrest with successful resuscitation, profound neonatal asphyxia, and carbon monoxide inhalation. Most frequently the sites of brain involvement are the basal ganglia and parasagittal areas. Border zone area hyperintensities are revealed on T2-weighted images. Striking enhancement can occur after contrast administration.

Differentiating between ischemia and a neoplasm can at times be difficult. Often imaging findings that suggest stroke includes a full thickness lesion that affects gray and white matter and follows a typical vascular distribution. The cortex is affected and the underlying white matter spared in a stroke, while tumors tend to involve the white matter and spare the cortex. A stroke tends to be wedge-shaped or serpentine, whereas a tumor is usually round, lobulated, or infiltrating.

MR may also be of benefit in the evaluation of other vascular lesions such as arteriovenous malformations, aneurysms, vasculitis, and direct vessel injury (Fig. 14).

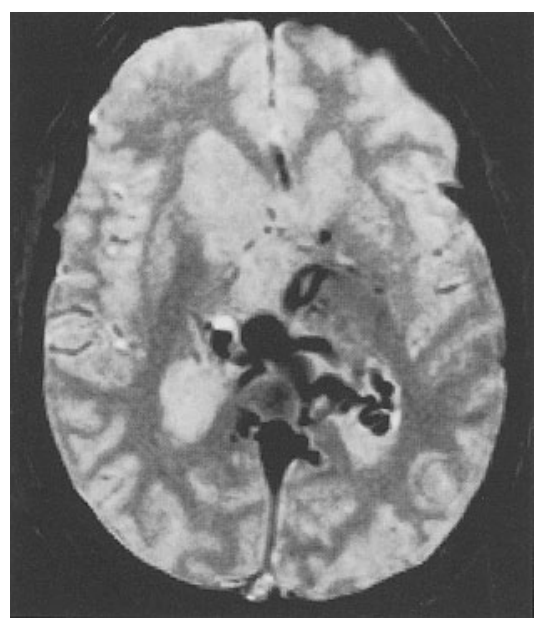

Fig. 14. Gradient echo MR (TR 610, TE 35, FA 30) demonstrating a large arteriovenous malformation. Note the probable area of focal hemorrhage seen as marked hyperintensity. (Imaged from a 0.3-T Hitachi open MR system)

\section{Head Trauma}

With two million cases in the United States each year, traumatic brain injury is one of the most common types of insult in the United States. MR and particularly open design MR is frequently becoming utilized for this injury [76]. MR can better identify several types of lesions associated with head trauma than CT, including contusions, shearing injury of the white matter, subdural hematomas, and anoxic injury [111] (Fig. 15).

The reasons emergency patients with head injury were in the past evaluated by CT were both logistical and clinical. Siting requirements at one time dictated that MR scanners be located a considerable distance from emergency rooms. Also, it was difficult and sometimes impossible to manage these acutely injured patients effectively in most MR scanners. However, it is now possible to locate an open-field magnet near an emergency department providing the opportunity to compare patients who undergo examination by the respective modalities [111].

While previous studies of MRI indicated that this modality was more sensitive than CT in detecting many types of traumatic lesions [112124], blinded studies support the claim that a positive MR is more predictive of actual trauma than a positive CT for all forms of traumatic injury, excluding fracture [111]. The appropriate acute surgical management in cases of head trauma continues for the most part to rely on CT as the diagnostic modality of choice [125-129]. CT appears to be satisfactory as the initial diagnostic test in the comatose or dramatically neurologi-

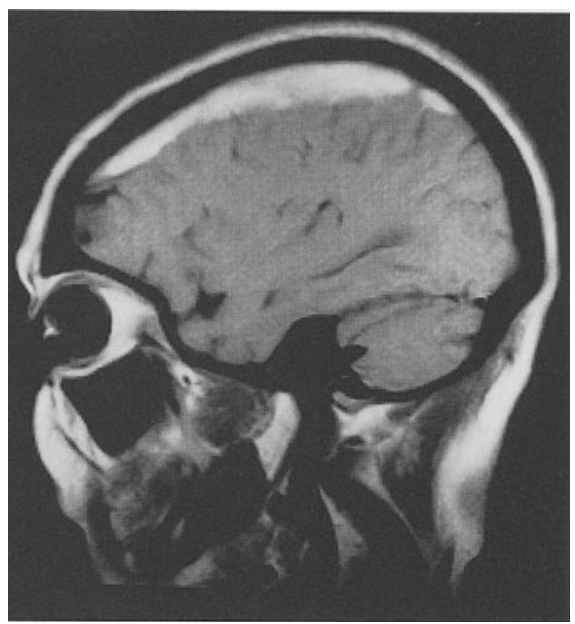

Fig. 15. T1-weighted MR (TR 650, TE 25) demonstrating a subdural hematoma. (Image from a 0.3-T Hitachi open MR system) 


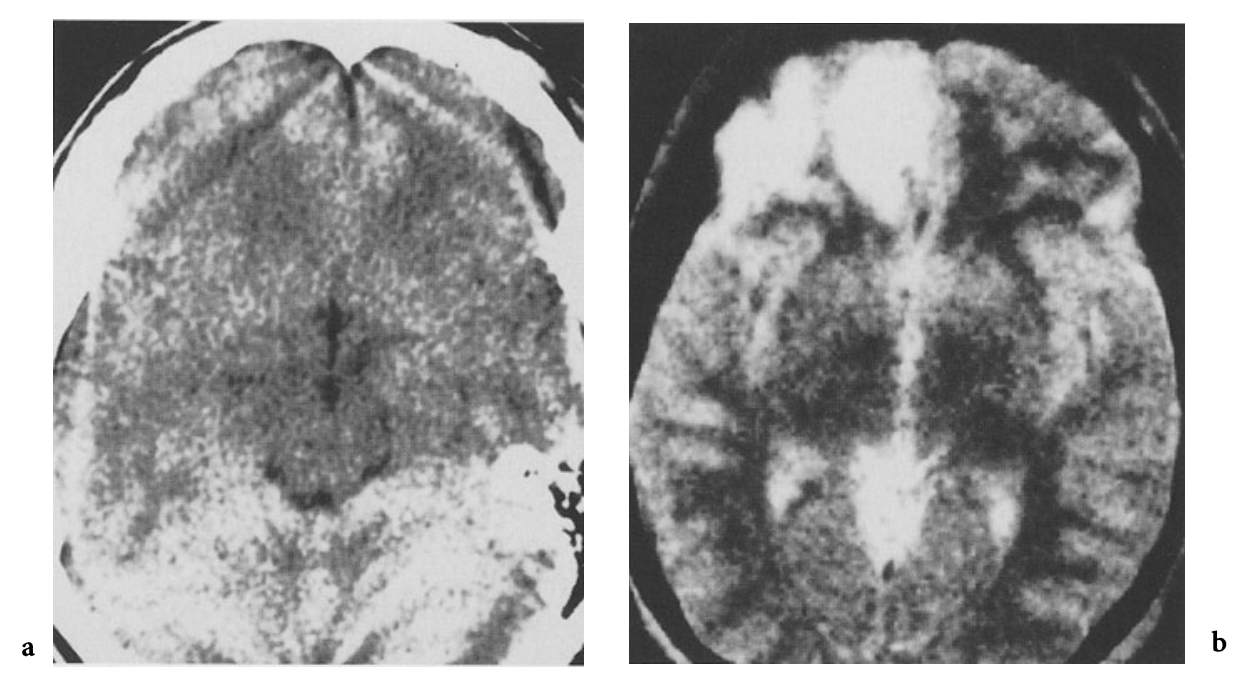

Fig. 16. a CT demonstrating no significant abnormality. (Image from a 0.3-T Hitachi open MR system.). b T2weighted (TR 2000, TE 105) open-design MRI demonstrat-

cally impaired head-injured patient due to current widespread availability, speed, and accessibility. It must be recognized that the inability of CT to detect multiple types of cerebral injury has been substantiated by pathological confirmation [115, 130-132]. Acute brain injury can be more accurately assessed with MR, improving quantitative and qualitative analysis of the extent of acute brain injury. It is no longer adequate to use a normal CT scan as evidence that patients with head injury do not suffer severe neuropsychological or delayed neurological impairments as a result of undetected cerebral lesions (Fig. 16).

In the United States over half of the significant head injuries occur as a result of automobile accidents [133]. A sensitive and objective tool is necessary not only to sort out the relevance of persistent complaints when litigation is in process or pending; more importantly, alteration in medical treatment of these patients may be indicated by lesions that are undetected by CT. Patients with significant cerebral lesions may warrant closer observation, more aggressive and earlier rehabilitation efforts, and a more gradual or prolonged convalescent period, possibly even fluid restriction [111].

In determining the value of an open-field scanner in the emergency setting, what becomes apparent is a need for a systematic approach. These patients should receive initial CT scans as soon as possible, followed by MR within the first $24 \mathrm{~h}$. When MR is performed and CT scans are not available, our protocol calls for an axial T1weighted scan. This significantly improves the detection of SAH and ICH at lower field strengths ing extensive cerebral contusions performed on the same day as a. (Image from a Toshiba $0.64-\mathrm{T}$ open design MR system)

[134-136] (see Fig. 3). To accommodate the large number of cranial MR referrals from this protocol it has been necessary to establish a limited MR examination. This limited examination consists of axial proton density and $\mathrm{T} 2$-weighted images and is performed only when a CT scan is available from the preceding $24 \mathrm{~h}$. This is charged as a combination study, and represents a $50 \%$ reduction in cost of the two examinations performed separately.

Provided a CT scan has been performed, our study indicates that MRI performed within $24 \mathrm{~h}$ of the initial head trauma should be adequate. It has also been demonstrated conclusively that a negative CT scan is not sufficient to exclude large contusions, shearing injury, and extra-axial fluid collection [111]. These disorders may require less acute neurosurgical or medical intervention.

The additional information provided by an MR scanner in the emergency room may alter patient care significantly. The open design system allows the management of acutely injured patients. While CT and MR are complementary in the evaluation of head trauma, MR has been demonstrated to be significantly more sensitive for a broad range of common posttraumatic brain insults [111].

\section{Hemorrhage}

The appearance of hemorrhage may be the most difficult area to understand in all of MR brain imaging. The several published studies on the appearance of blood on MR attest that there is as much disagreement as there is agreement on 
this topic. To a large extent this is due to the fact that field strength has been ignored when hemorrhage on MR is considered. A common pattern in the appearance of intraparenchymal hemorrhage is identifiable when the field strength of the scanner is included [136].

T1- and T2-weighted images show hyperintensity in the hyperacute stage of hemorrhage (bleeding that is less than $24 \mathrm{~h}$ in age). As the field strength decreases, $\mathrm{T} 1$ is much more hyperintense, with $\mathrm{T} 2$ rapidly losing intensity as the field strength increases. Hyperacute blood is therefore white on $\mathrm{T} 1$ at low-field strength and white on T2 at both high and low-field strengths, but not for long at higher field strengths (see Fig. 3) [76].

Aging blood becomes acute ( 1 day to 1 week) and loses intensity on both $\mathrm{T} 1$ and $\mathrm{T} 2$ sequences at all field strengths. At higher field strengths it becomes darker more rapidly on T1- and particularly on T2-weighted sequences. This is attributed to a combination of clot retraction and deoxyhemoglobin formation as well as red blood cell settling and packing (Fig. 17) [76].

Blood continues to age and becomes subacute (2 weeks-1 month) as it goes through several phases. Intracellular methemoglobin begins to form, and T1-weighted sequences show the blood as white (increased signal intensity or hyperintensity), while the T2 sequences show decreased signal continually (Fig. 18). Then the methemoglobin becomes extracellular as the red blood cells lyse, and blood becomes hyperintense (white) on T2 sequences also [76].

Blood is generally referred to as chronic when it becomes more than 1 month old. When it is chronic, it remains hyperintense on both T1- and T2- weighted sequences until replaced by CSF. Then it is usually hyperintense (white) on T2 and hypointense (black) on T1. Figure 19 summarizes the changes that blood goes through on MR, and illustrates the effect of field strength on the appearance of blood over time. For the most part, blood exhibits the exact same changes at all field strengths, with a more rapid time course at lower field strengths. This can be summarized on T1 and $\mathrm{T} 2$ sequences in the following manner and visualized in Fig. 19.

On T1, blood begins as hyperintense (especially on low field) where this increased signal persists much longer than at high field) and decreases rapidly to hypointensity. During this same time T2 sequences show acute blood also going from hyper- to hypointense but decreasing to a much lower intensity on T2 (black blood) as compared to the signal decrease on $\mathrm{T} 1$. This process

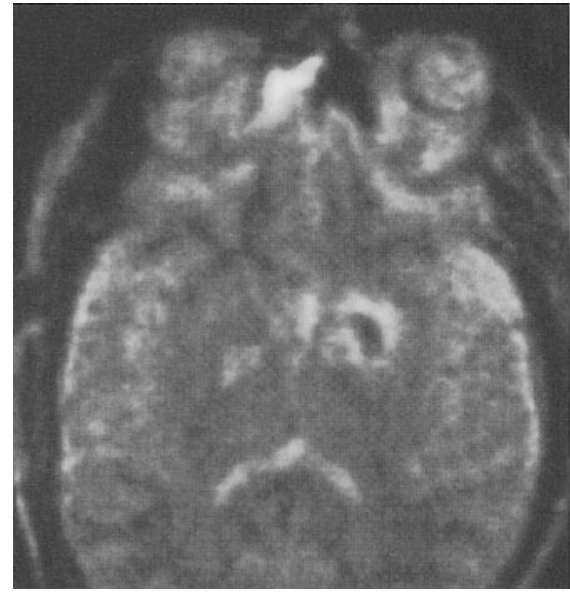

Fig. 17. T2 MRI (TR 2000, TE 105) demonstrating decreased signal intensity in a hemorrhagic focus. (Image from a Toshiba 0.64 -T open-design MR system)

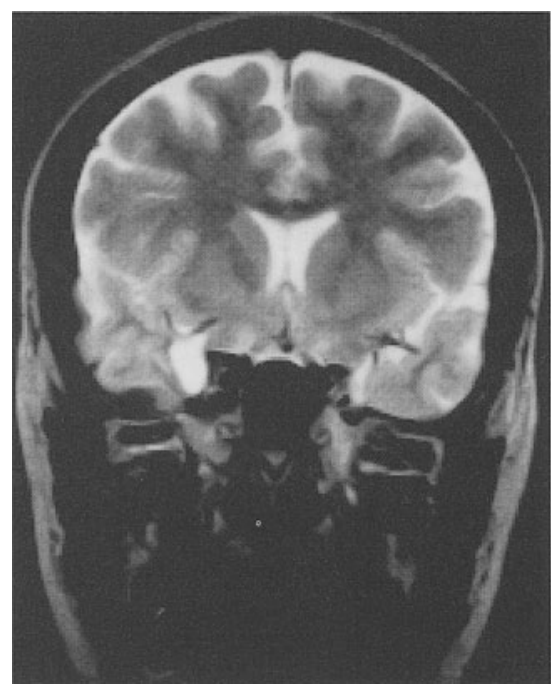

Fig. 18. High signal intensity of methemoglobin on T2 sequence (TR 3900, TE 117) resulting from an aneurysm. (Image from a $0.3 \mathrm{~T}$ Hitachi open MR system)

of signal loss represents well oxygenated intact red blood cells (hyperintense on $\mathrm{T} 1$ and $\mathrm{T} 2$ ) going through a process of oxygen loss, red cell dehydration, and clot formation with clot retraction (hypointense on $\mathrm{T} 1$ and $\mathrm{T} 2$ ). At this stage the deoxyhemoglobin in the retracted clot filled with dehydrated cells appears of low signal on $\mathrm{T} 1$ and black on T2. As methemoglobin begins to form in the intact red blood cells, T1 signal increases until the lesion begins to appear hyperintense (white) while on T2 the lesion remains hypointense (black). With lysis of the red blood cells, free methemoglobin forms, and this is hyperintense on both T1 and T2. The lesion is now there- 


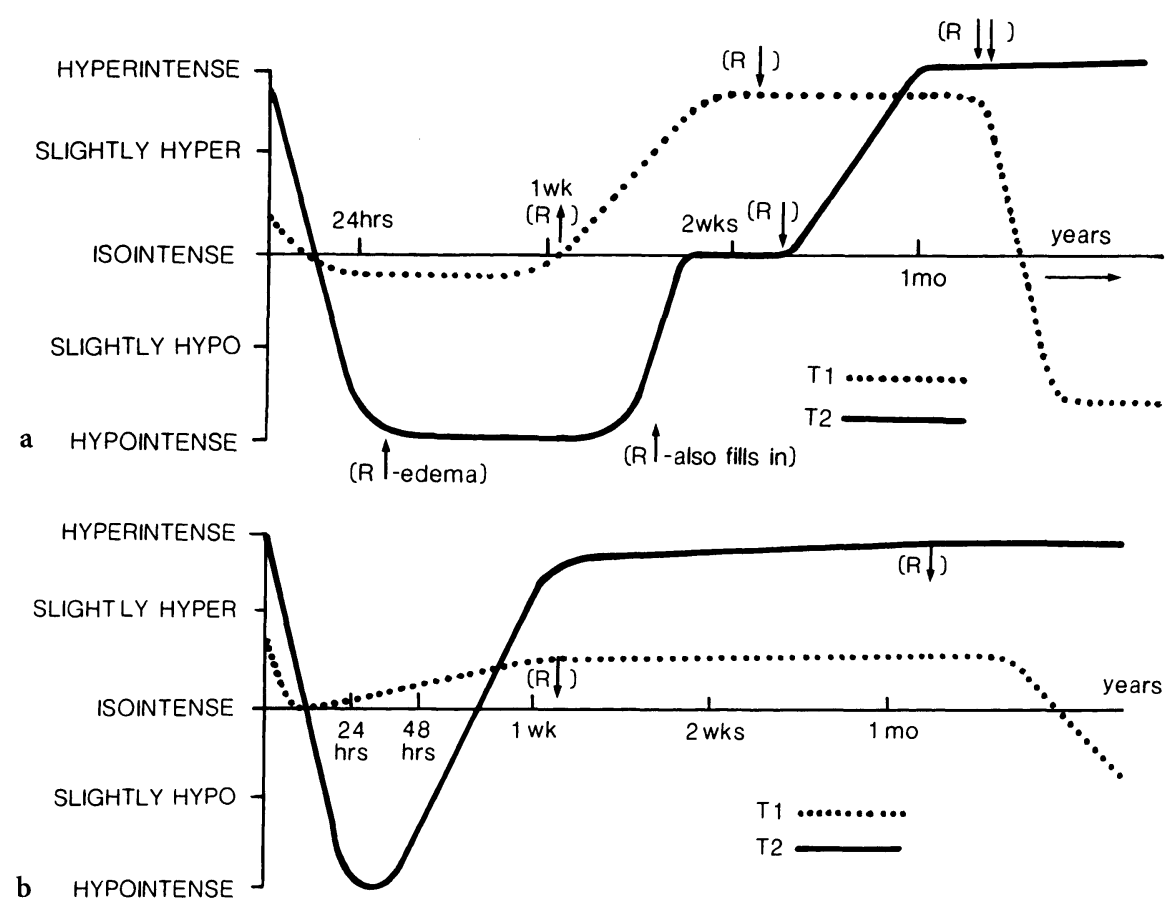

Fig. 19. a Graph indicating the temporal pattern of hemorrhage at high field ( $R$, rim of lesion). b Graph indicating the temporal pattern of hemorrhage as seen on low-field open-design systems ( $R$, rim of lesion)

fore white on both $\mathrm{T} 1$ and $\mathrm{T} 2$. A hemosiderin ring forms around both $\mathrm{T} 1$ and $\mathrm{T} 2$ but is far more evident on T2 as the blood ages. Finally, if replaced by CSF, the lesion is hypointense on T1 but remains hyperintense on $\mathrm{T} 2$.

In conclusion, definite temporal patterns for the evolution of hemorrhage exist. The variability that is so marked and observed in hemorrhages can be explained by several factors including time, biochemical change, and structural alterations in the evolving hematoma [136]. The patterns identified above can aid in the approach, identification, and final diagnosis of an intracranial hemorrhage [136]. In time the heterogeneity in the appearance of hemorrhage may provide insight into the pathophysiological changes occurring in the brain.

\section{White Matter Disease}

$M R$ is the most effective imaging technique with regards to white matter disease. White matter disease may be classified as either demyelinating or dysmyelinating. The term dysmyelinating disease is used to describe a group of conditions in which there is a lack of normal myelin (white matter) formulation in the brain. Conditions such as metachromatic leukodystrophy, Krabbe's disease (globoid cell leukodystrophy), Canavan's dis- ease (spongiform leukodystrophy), Alexander's disease (fibrinoid leukodystrophy), and adrenal leukodystrophy are examples of dysmyelinating disease. All of these disorders have in common a lack or delay in the formation of normal white matter that results in severe neurological abnormalities and/or early death [138].

In contrast to the dysmyelinating diseases, where no normal myelin forms, demyelinating conditions are diseases in which there is a loss of normally formed myelin. These are commonly referred to as primary or secondary. Primary demyelinating diseases are those that destroy the myelin sheath, tend to spare other parts of the nervous system such as nerve cells and supporting structures, and demonstrate a relative lack of wallerian degeneration [139-141]. Secondary refers to conditions that may result in a loss of myelin, and this category includes ischemia, anoxia, infection, toxic agents, and diseases of unknown etiology (Fig. 20). The term "white matter disease" could include most diseases of the central nervous system, when it is used in reference to secondary demyelinating processes [139-145].

Multiple sclerosis (MS) is the most common condition that results in the loss of normally formed myelin [138, 146] (Fig. 21). While the cause of MS remains unknown, it is believed to involve autoimmune-mediated demyelination in 


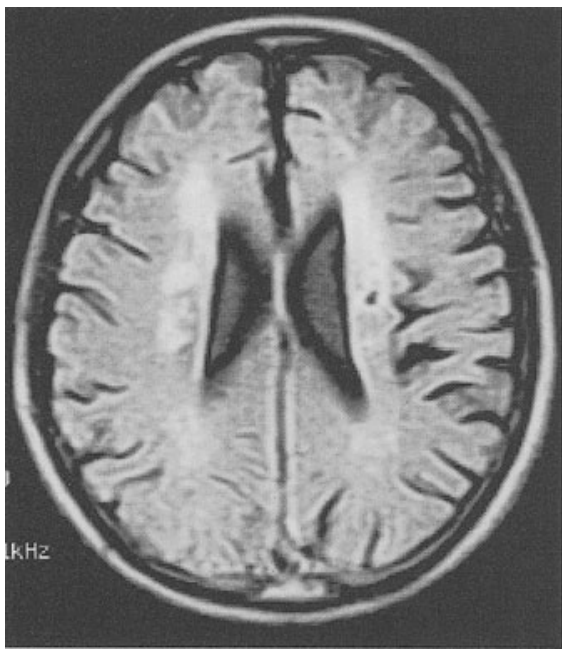

Fig. 20. FLAIR image (TR 5500, TE 112, TI 1550) demonstrating periventricular and subcortical white matter disease on a GE 0.2 -T open MRI system

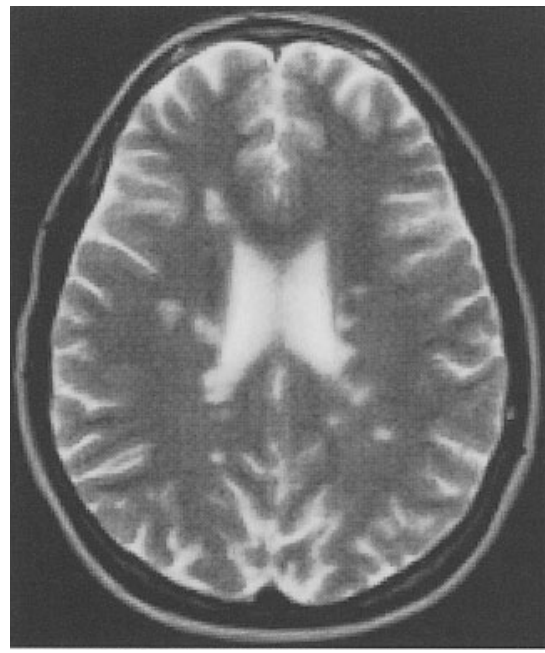

Fig. 21. Axial T2-weighted MR (TR 5605, TE 117) of MS plaques from a $0.2-\mathrm{T}$ Siemens open MR system. (Donald Schnapf, DO, York Imaging Center, Pennsylvania, used with permission)

genetically susceptible individuals [146-150]. The role of inheritance is not understood, even though an increased incidence of subclinical demyelination has been demonstrated in asymptomatic first-order relatives of MS patients [148]. Patients with this disease present with highly variable forms of clinical presentation; indeed, it is the broad variety of neurological symptoms that occur at different times that often lead to a suspicion of MS.

A prospective 2-year study demonstrated the sensitivity of MRI in detecting MS to be nearly $85 \%$ and exceeding all other tests, including CT

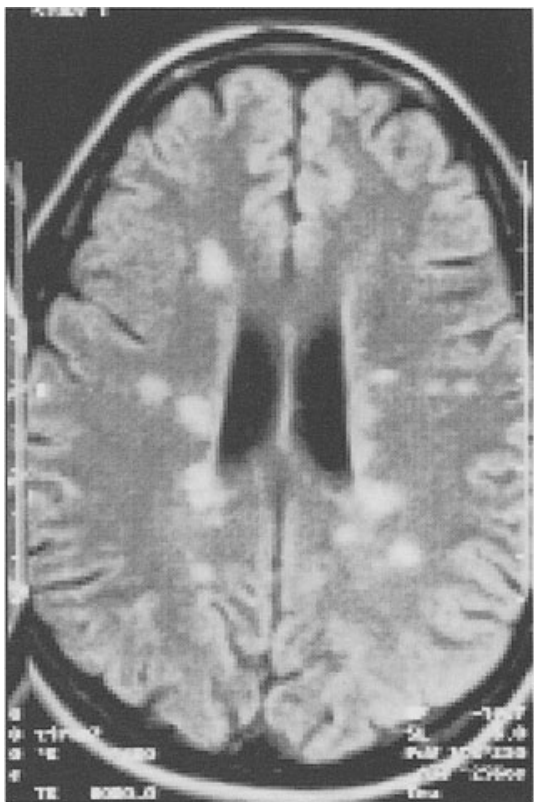

Fig. 22. A FLAIR image (TR 6000, TE 93) demonstrating "Dawson's fingers" from a 0.2-T Siemens scanner. (Donald Schnapf, DO, York Imaging Center, Pennsylvania, used with permission)

[151]. On standard MR scans most foci that are identified are clinically silent $[152,153]$. Most often MS "plaques" are iso- to hypointense on T1weighted scans and hyperintense compared to brain on T2-weighted scans (Fig. 4). In order to establish the MR diagnosis of MS most require the presence of three or more discrete lesions that are $5 \mathrm{~mm}$ or greater in size, as well as lesions that occur in a characteristic location and have a compatible clinical history $[154,155]$. It is typical to find oblong lesions at the callososeptal interface. Also characteristic is pervenular extension into the deep white matter, the so-called Dawson's finger [155] (Fig. 22).

The MS lesions often appear as round or ovoid areas with a "beveled" (lesion within a lesion) appearance on $\mathrm{T} 1$ - and proton density weighted studies. In severe cases confluent periventricular lesions are common (Fig. 23). In about $10 \%$ of long-standing severe MS cases, abnormal basal ganglia hypointensity is seen. Following contrast administration enhancement represents bloodbrain barrier disruption. Enhancement is seen during the active dysmyelinating stage as highly variable and typically transient [138]. Solid as well as ringlike enhancement patterns are evident [156]. While most MS plaques do not enhance following contrast administration [154], enhanced T1-weighted scans can detect additional lesions that are not apparent on $\mathrm{T} 2$ weighted imaging 


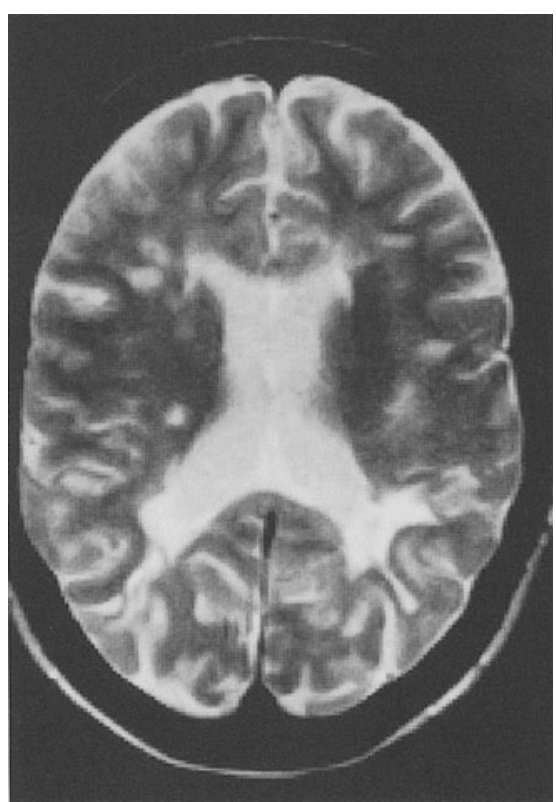

Fig. 23. A T2 MR (TR 2880, TE 90) demonstrating all features of MS including confluent periventricular lesions. (Image obtained from a 0.3-T Hitachi open MR system)

[152]. Certain solitary or very atypical MS lesions may be indistinguishable from abscess or neoplasm [157, 158].

Optic neuritis particularly and other cranial neuropathies are common in patients with MS. On T2-weighted imaging lesions in the brainstem tracts and nuclei are seen, whereas contrast-enhanced T1-weighted studies may delineate enhancement in the nerves themselves. What proves useful in separating optic nerve enhancement from high-signal orbital fat are fat-saturation and short-inversion recovery scans [159]. The use of black CSF techniques or FLAIR results in white lesions against a black CSF signal that makes missing the lesions nearly impossible (see Figs. 2, $13,20,22)$.

Imaging of internal auditory canal and pituitary structures were in the past limited to highfield systems. However, imaging of these regions is now readily accomplished using open-design low-field scanners (see Figs. 5, 6, 24).

\section{- Pituitary Imaging}

Improved tissue contrast and multiplanar capability make MR the preferred imaging method for evaluating patients with suspected sellar and parasellar abnormalities. In patients with symptoms or signs of pituitary dysfunction or visual field deficits MR is the primary imaging modali-

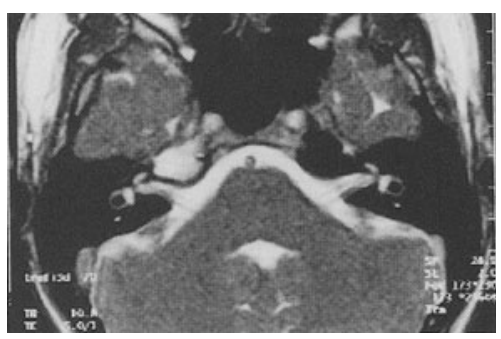

Fig. 24. Fast spin echo sequence demonstrating seventh and eighth nerves on a $0.2 \mathrm{~T}$ Siemens open MR system. (Michael Deimling, PhD, Siemens, Erlangen, Germany, used with permission)

ty, while coronal CT remains the diagnostic imaging method of choice in patients in whom an MR study is contraindicated. The following protocols have been successfully employed at field strengths from 0.6 to $1.5 \mathrm{~T}$ for the evaluation of the pituitary. Routine dynamic scanning has been performed regardless of field strength with scans being initiated after IV injection of a bolus of $0.1 \mathrm{mmol} / \mathrm{kg}$ gadolinium DTPA. A CT dynamic protocol has also been included here for the rare patient in whom MR is contraindicated.

\section{Protocol: Pituitary High-Field MR (Siemens)}

1. Sagittal localizer.

2. T1 coronal dynamic (begin when Gd bolus is started): TR $1200 \mathrm{TE} 1$ matrix $128 \times 256$, FOV 300 , thickness $3 \mathrm{~mm}$, ACQ 1 , slices $5(\times 8)$, time $29 \mathrm{~s} \times 8$.

3. $\mathrm{T} 1$ coronal routine: TR 300 TE 15 matrix $192 \times 256$, FOV 300 , thickness $3 \mathrm{~mm}$, ACQ 4, slices 10 ( $4 \mathrm{~min})$.

4. Routine T1 sagittal: TR 700, TE 15, matrix $256 \times 256$, FOV 240, thickness $5 \mathrm{~mm}$, ACQ 2, slices 23 (6 $\mathrm{min})$.

5. Proton density and T2 axial: TR 2500, TE 22/90 matrix $192 \times 256$, FOV 240, thickness $5 \mathrm{~mm}$, ACQ 1, slices 20 (8 $\mathrm{min})$.

\section{Protocol: Pituitary High-Field MR (GE)}

1. Sagittal localizer.

2. T1 coronal dynamic (begin when Gd bolus is started): TR 32, TE 6, FA 20 (SPGR), matrix $256 \times 128$, FOV 240, thickness $3 \mathrm{~mm}$, ACQ 2 (2 slice locations), single-slice technique, time$25 \mathrm{~s}$ (per slice) $\times 8$ (sequence time $1 \mathrm{~min}$; scan time $5 \mathrm{~min}$ ).

3. $\mathrm{T} 1$-coronal routine: $\mathrm{TR} 600, \mathrm{TE} 12$, matrix $256 \times 128$, FOV 160, thickness $3 \mathrm{~mm}$, ACQ 4, slices 14 (5 $\mathrm{min})$.

4. Routine T1 sagittal: TR 600, TE 12 matrix $256 \times 128$, FOV 160, thickness $3 \mathrm{~mm}$, ACQ 4, slices 14 (5 $\mathrm{min})$. 
5. Proton density and T2 axial: TR 2800, TE 30/ 100, matrix $256 \times 192$, FOV 200, thickness $5 \mathrm{~mm}$, ACQ 0.075, slices 20 (7 min).

\section{Protocol: Pituitary Open Low-Field MR} (Toshiba)

1. Center the pituitary gland by scout view or fluoro-mode.

2. Three-axis locator (scout view).

3. TR 150, TE 30 , matrix $256 \times 256$, FOV 125 , thickness $10 \mathrm{~mm}$, ACQ 1 , slices $-1(\times 8)$ time $38 \mathrm{~s}(\times 8)$.

4. T1 coronal routine: TR $110, \mathrm{TE} 15, \mathrm{FA} 60$, matrix $256 \times 256$, FOV 110, thickness $2.5 \mathrm{~mm}$, ACQ 2, slices 16 ( $9 \mathrm{~min}, 56 \mathrm{~s}$ ).

5. Reconstruct coronal, sagittal, and axial planes at $1.25 \mathrm{~mm}$, film at $4 \times$ magnification.

Protocol: Pituitary Open Low-field MR (Picker)

1. Center the pituitary gland by scout view or fluoro-mode.

2. T1 coronal dynamic TR 250, TE 15, FA 35, matrix 25/256, FOV 300, thickness $3 \mathrm{~mm}$, ACQ 1, slices $1 \times 5$, time 1:04 $(\times 5)$.

3 . Reconstruct sagittal and axial planes.

\section{Protocol: Coronal Sellar CT}

1. Position patient supine with head at maximum extension with shoulder elevation.

2. Scout view.

3. Gantry tilt $140^{\circ}$ posterior or true coronal plane.

4. Program dynamic technique (8-13 slices as required for pituitary fossa).

5. Bolus with $40 \mathrm{~g}$ iodinated contrast.

6. Begin scanning with thinnest slices as rapidly as possible through the pituitary fossa.

7. Following dynamic scan, repeat high-resolution coronal CT.

8. Photograph at $2 \times$ magnification.

9. Reconstruct sagittal and axial images.

10. Measure gland height at stalk and at maximum size.

A wide variety of pathological processes have been described in the sellar and parasellar region [160-163].

The abnormal finding that is most striking on both dynamic and routine neuroimaging of the pituitary gland is a focal defect in the gland following contrast administration. The diagnosis is frequently that of a pituitary adenoma, when this finding is combined with other abnormalities of the gland (Fig. 25) [164]. A pituitary adenoma, clinically categorized as functioning or nonfunctioning, may be defined as a benign neoplasm of

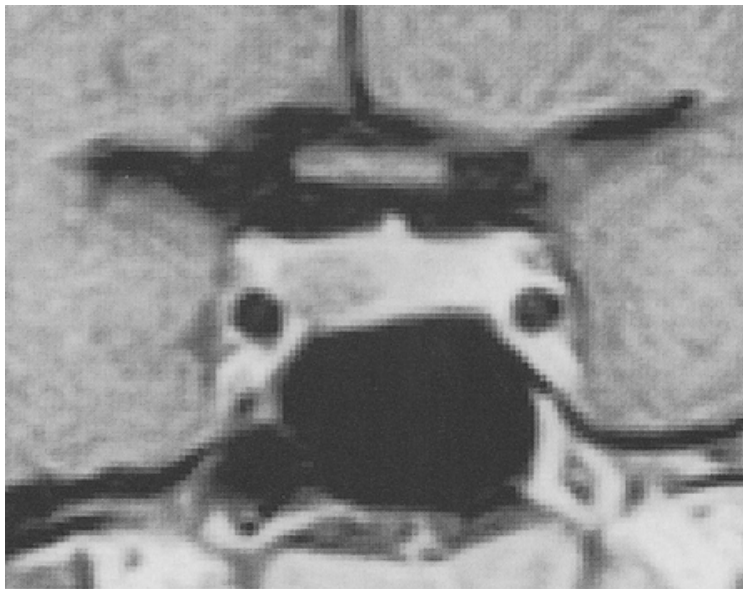

Fig. 25. A T1 postcontrast MR (TR 472, TE 26) demonstrating a pituitary microadenoma identified as a focal area of decreased signal within the enhancing pituitary gland. (Image from a $0.2-\mathrm{T}$ Siemens open MR system. Mark Leszczynski, RT, Memorial Open MRI, Houston, Texas, used with permission)

the anterior pituitary gland (adenohypophysis). Radiologically an adenoma is described as a microadenoma or macroadenoma based on size. A microadenoma is less than $10 \mathrm{~mm}$ in diameter and a macroadenoma is greater than $10 \mathrm{~mm}$ in diameter. More often the microadenomas are functioning and typically secrete prolactin, growth hormone, or ACTH. Macroadenomas, less often functioning, are more likely to present with neurological signs and symptoms from mass effect on the optic chiasm or cranial nerves (Fig. 26) [164-166]. Prior to contrast enhancement macroadenomas can be expected to demonstrate isointensity or hyperintensity relative to cerebral gray matter. Signal inhomogeneity may present as a result of tumor necrosis, cyst formation, or hemorrhage. Minimal to moderate enhancement is typical following the administration of gadolinium on MR. The objective of an MR examination is primarily to evaluate possible suprasellar or parasellar extension, even though these lesions are readily identifiable without contrast in many instances. It is possible to best evaluate compression of the optic chiasm, invasion of the cavernous sinuses, or extension into the sphenoid sinus following administration of intravenous contrast by MR. The possibility of an aneurysm should be indicated by the presence of a large flow void on MR, and MR angiography can be performed at the same setting.

Findings most commonly encountered in the evaluation of microadenomas, which may be common to both microadenomas and macroadenomas, include: (a) focal defect in the gland follow- 


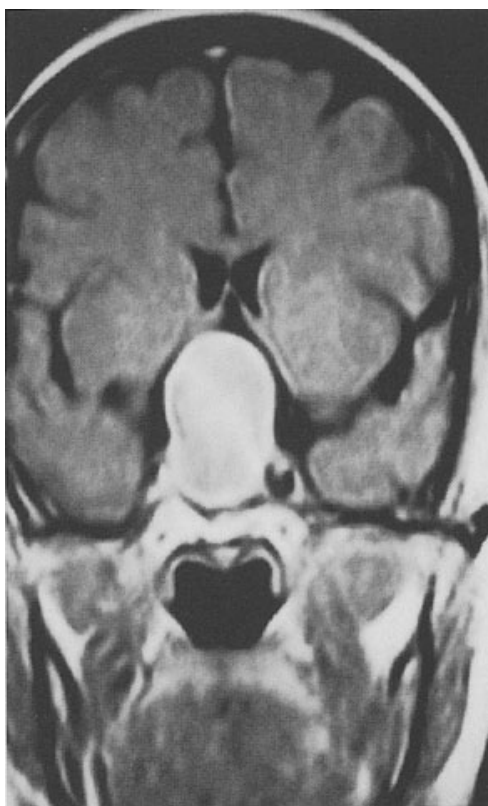

Fig. 26. T1-weighted MR (TR 68, TE 24, FA 30) postgadolinium contrast enhancement demonstrating a pituitary macroadenoma. (Image from on a 0.64-T Toshiba open design MR system)

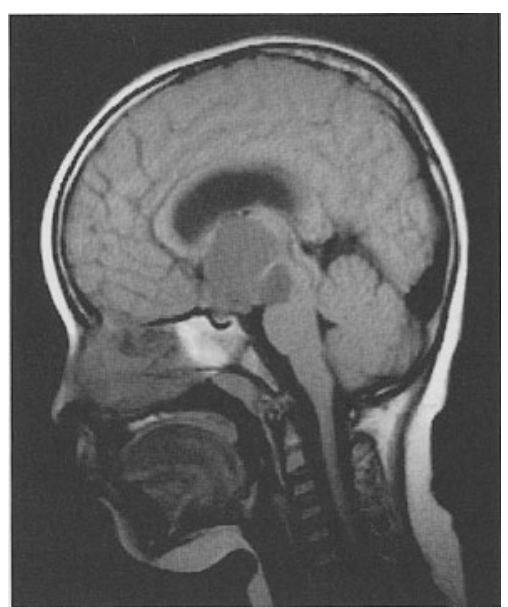

Fig. 27. T1-weighted MR (TR 600, TE 30) demonstrating a large suprasellar cystic mass. (Image from a 0.35-T Fonar MR system)

ing contrast enhancement (particularly evident on dynamic images), (b) upward convexity of the superior margin of the pituitary gland, (c) asymmetric gland enlargement, (d) increased gland height, (e) stalk deviation, and (f) focal erosion of the floor of the sella (often difficult to appreciate on MR). When more of the findings are present, there is a greater likelihood of pituitary adenoma. However, as stated above, the strongest indicator of pituitary microadenoma is a focal region of hy- pointensity following contrast administration [164, 165, 167-169].

A precursor of pituitary adenoma may be represented by pituitary hyperplasia. Pituitary hyperplasia or hypertrophy may be the result of normal hormonal influences occurring during early development, puberty, and pregnancy $[170$, 171]. Abnormal extrapituitary influences may also result in pituitary hyperplasia, occurring as a result of bronchial carcinomas, islet cell tumors, and carcinoid tumors, for example [172]. Following contrast enhancement pituitary hyperplasia demonstrates a uniformly enlarged and enhancing gland without evidence of a focal defect. In a uniformly enlarged pituitary gland, dynamic images are particularly valuable in excluding a focal defect.

The location of craniopharyngiomas may be both intrasellar and suprasellar [161, 167, 173]. Craniopharyngiomas arise from squamous epithelial clefts of Rathke's pouch and are slowly growing benign neoplasms. These tumors present primarily in children or young adults, but may also be seen in middle or later age groups. These neoplasms contain both cystic and solid components with the cystic areas containing cholesterol or blood. The signal intensity of the cystic component is variable on MR but may also be hyperintense as a result of cholesterol or blood. Cystic regions are typically hypodense on CT. Craniopharyngiomas are most often heterogeneous, and this is not related to location [161, 167, 173] (Fig. 27).

In addition to adenomas and craniopharyngiomas, tumors such as meningiomas, metastatic disease, gliomas, lymphomas, pinealomas, choristomas, dermoids, epidermoids, teratomas, and lipomas also occur in this location.

A sella that is partially or completely filled with cerebrospinal fluid is referred to as an "empty sella." Frequently the gland is small and positioned posteriorly and inferiorly against the sellar floor. An empty sella is rarely accompanied by endocrine dysfunction or an associated pituitary adenoma.

\section{- Diagnostic Yield and Reader Experience}

Diagnostic efficacy is considered of primary importance in the evaluation of any imaging modality. This remains a concern regardless of other issues that may be involved, including risk and cost. Therefore imaging systems that may offer a significant reduction in cost and risk would generally be considered of little value unless at least an acceptable level of diagnostic efficacy had been demonstrated. Well-controlled and blinded studies 
have shown similar diagnostic accuracy for low, middle-, and high-field MR systems [174].

The development of MRI has been paralleled with controversy regarding optimum field strength since the first clinical applications of MR in $1982[175,176]$. After more than 15 years of continued research and clinical use this issue remains unresolved [175-178]. In a study comparing the diagnostic efficacy of MRI at $0.064 \mathrm{~T}$ with $\mathrm{CT}$ and with MRI at $1.5 \mathrm{~T}$ in cranial central nervous system disease, statistical measurements of sensitivity, specificity, and reader confidence were addressed [179].

The results from this study indicate that the difference in diagnostic capability of MR imagers at field strengths of 0.064 and $1.5 \mathrm{~T}$ is small for most central nervous system diseases and between $0 \%$ and $10 \%$ in most cases. Many additional factors must be considered when evaluating diagnostic accuracy for clinical care, including the radiologist's experience, the patient population, availability of the clinical history, and effective use of the MR imager, which includes thoroughness of the examination, appropriate use of pulse sequences, and use of MRI contrast material. Instead of establishing the superiority of one imaging system, technique, or field strength, research generally demonstrates that each system provides diagnostically valuable images, and that it is critical to know how to use each system to its best advantage [175, 176, 180-188].

It is important to include consideration not only of the quality of the images but the clinical history of the patient and the capability of the radiologist when assessing diagnostic accuracy. In the above study an incomplete or inadequate history accounted for as much as $100 \%$ loss in sensitivity in the category of abscess or infection. We found as much as $15 \%$ loss of diagnostic sensitivity as a result of variations in reader capability, diligence, and attention. Therefore issues such as history and reader variability accounted for far more than scanner type in missed diagnoses. Radiologists and physicians in a competitive environment are aware that quality of interpretation, availability of comparative studies, direct and complete clinical history, and radiological training have measureless influence on individual patient care. Issues of quality assurance have been partly deflected by the predominant focus on type of imager and field strength with those issues that actually make the most clinical difference avoided. In other words, both the literature and common experience confirm that no amount of scanner improvements can account for inherent deficiencies in the physician reading the scan.
While inherent scanner limitations do exist, there appear to be little in the way of diagnostic differences between high- and low-field MR images. The specificity of low-field MRI and even CT may be substantially superior to that with high-field MRI in some cases [179].

The literature indicates that bore-type highfield and open-design low-field MR imagers are diagnostically equivalent for detection of central nervous system disease [189]. Many additional factors must be considered when evaluating this conclusion, such as the experience of the radiologist, the type of patient being evaluated, the availability of appropriate history, maximum utilization of the MR scanner, length of the study, and patient safety. Literature studies have generally found that most imaging systems provide diagnostically valuable information at varying field strengths and for a broad range of diseases [1-5, $12,136,189-195]$.

It is not surprising that differences in reader interpretation and the effect of information such as appropriate clinical history are more significant than the diagnostic imaging modality utilized. However, time, cost-effectiveness, and safety are additional factors that should be considered in MR applications.

Even the most technologically advanced and sophisticated imaging technology has serious limitations. We must continue to recognize a patient's uniqueness and the distinctiveness of each individual's condition. Each person's brain is capable of markedly different physiological and functional responses to the presence of pathology; this may significantly influence treatment outcomes and options. Open design MR systems provide yet another tool to assist in the care of our wonderfully complex patients.

\section{References}

1. Lotz H, Ekelund L, Hietala SO, Wickman G (1988) Lowfield (0.02) MR imaging of the whole body. J Comput Assist Tomogr 12 (6):1006-1013

2. Seppon RE, Sipponen JT, Sivula A (1985) Low-field (0.02) nuclear magnetic resonance imaging of the brain. J Comput Assist Tomogr 9:237-241

3. Sipponen JT, Sepponen RE, Tantu JL, Sivula A (1985) Intracranial hematomas studied by MR imaging at 0.17 and 0.02 T. J Comput Assist Tomogr 9:698-704

4. Kormano M, Raininko R, Katevuo K (1987) Magnetic resonance imaging of intracranial neoplasms at $0.02 \mathrm{~T}$. Acta Radiol 28:369-374

5. Barfuss H, Fisher H, Hentschel D et al (1988) Wholebody MR imaging and spectroscopy with a 4-T system. Radiology 169:811-816

6. Mitchell MD (1996) Efficacy studies of low-fieldstrength MR imaging: feast or famine. Radiology 200 (1):284 
7. Drejer J, Thomsen HS, Tanttu J (1995) Low-field imaging of the spine: a comparative study of a traditional and a new, completely balanced gradient-echo sequence. Acta Radiol 36:505-509

8. Fagerlund M, Björnebrink, Elelund L, Toolanen G (1992) Ultra low field MR imaging of cervical spine involvement in rheumatoid arthritis. Acta Radiol 33 (2):89-92

9. Hittmair K, Turetschek K, Gomiscek G, Stiglbauer R, Schurawitzki H (1996) Field strength dependence of MRI contrast enhancement: phantom measurements and application to dynamic breast imaging. $\mathrm{Br} \mathrm{J}$ Radiol 69 (819):215-220

10. Friedman DP, Rosetti GF, Flanders AE, Piccoli C, Rao VM, Mitchell DG et al (1995) MR imaging: quality assessment method and ratings at 33 centers. Radiology $196(1): 219-226$

11. Ignelzi RJ (1993) The potential role of low field MR with open design in assessing ligamentous injury in acute cervical trauma. Surg Neurol 39:519-529

12. Kent LD, Larson EB (1988) Magnetic resonance imaging of the brain and spine. Ann Intern Med 108:402424

13. Cooper LS, Chalmers TC, McCally M, Berrier J, Sacks HS (1988) The poor quality of early evaluations of magnetic resonance imaging. JAMA 259:3277-3280

14. Margulis AR (1988) About articles of judgment. Radiology 169:576-577

15. Freiherr G, Stephenson GM (1990) Indifference to safety heightens MR risks. Diagn Imaging 12 (6):79-83

16. New PFJ, Rosen BR, Brady TJ et al (1983) Potential hazards and artifacts of ferromagnetic and nonferromagnetic surgical and dental materials and devices in nuclear magnetic resonance imaging. Radiology 147:139148

17. Koenig SH, Brown RD, Adams D, Emerson D, Harrison CG (1984) Magnetic field dependence on $1 / \mathrm{T} 1$ in tissue. Invest Radiol 19:76-81

18. Rinck PA, Fischer HW, Elst LV, Van Haverbeke Y, Muller RN (1988) Field cycling relaxometry: medical applications. Radiology 168:843-849

19. Kaufman L, Arakawa M, Hale J, Rothschild P, Carlson J, Hake K, Kramer D, Lu W, Van Heteren J (1989) Accessible magnetic resonance imaging. Magn Reson Q 5:283297

20. Duffy KR, Spiller M, Lansen TA, Rifkinson-Mann S, Valsamis MP, Koenig SH, Kasoff SS, Brown RD, Tenner M (1992) Very low magnetic field strengths differentiate secreting from non-secreting pituitary adenomas. Proceedings of the 1992 meeting of the American Association of Neurological Surgeons, pp 334-335

21. Tsuchiya K, Mizutani Y, Hachiya J (1996) Preliminary evaluation of fluid-attenuated inversion-recovery MR in the diagnosis of intracranial tumors. AJNR Am J Neuroradiol 17:1081-1086

22. Kanal E, Shellock FG (1998) Magnetic resonance: bioeffects and safety. In: Orrison WW Jr (ed) Neuroimaging. Saunders, Philadelphia (in press)

23. Sell J. Contrast agents in neuroradiology. In: Orrison WW Jr (ed) Neuroimaging. Saunders, Philadelphia (in press)

24. Oksendal A, Hals P (1993) Biodistribution and toxicity of MR imaging contrast media. J Magn Reson Imaging 3:157-165

25. Harpur E, Worah D, Hals P, Holtz E, Furuhama K, Nomura H (1993) Preclinical safety assessment and pharmacokinetics of gadodiamide injection, a new magnetic resonance imaging contrast agent. Invest Radiol 28:S280-S343

26. Tweedle M, Eaton S, Eckelman W et al (1988) Comparative chemical structure and pharmacokinitics of MRI contrast agents. Investigative Radiology 23 [Suppl 1]:S236-S239
27. Tweedle M (1992) Physiochemical properties of gadoteridol and other magnetic resonance contrast agents. Invest Radiol 27 [Suppl 1]:S2-S6

28. Watson A, Rocklage S, Carvlin M (1991) Contrast media. In: Stark D, Bradley W (eds) Magnetic resonance imaging. Mosby, St Louis

29. McLachlan S, Lucas M, DeSimone D et al (1992) Worldwide safety experience with gadoteriodol injection (ProHance). In: Book of abstracts. Society of Magnetic Resonance in Medicine, p 1426

30. LaFlore J. Goldstein H, Rogan R, Keelan T, Ewell A (1989) A prospective evaluation of adverse experiences following the administration of Magnevist (gadopentetate dimeglumine) injection. In: Book of abstracts. Society of Magnetic Resonance in Medicine, p 1067

31. Niendorf $\mathrm{H}$, Dinger J, Haustein J, Cornelius I, Alhassan A, Claub W (1991) Tolerance data of Gd-DTPA: a review. Eur J Radiol 13:15-20

32. Takebayashi $S$, Sugiyama $M$, Nagase $M$, Matsubara $S$ (1990) Severe adverse reaction to IV gadopentetate dimeglumine. Am J Roentgenol 14:912-913

33. Shellock FG, Hahn P, Mink JH, Itskovich E (1993) Adverse reaction to intravenous gadoteridol. Radiology 189:1-2

34. Salonen O (1990) Case of anaphylaxis and four cases of allergic reaction following Gd-DTPA administration. J Comput Assist Tomogr 14:912-913

35. Tishler S, Hoffman JC (1990) Anaphylactoid reactions to IV gadopentetate dimeglumine. Am J Neuroradiol 11:1167

36. Tardy B, Guy C, Barral G. Page Y, Ollagnier M, Bertrand C (1992) Anaphylactic shock induced by intravenous gadopentetate dimeglumine. Lancet 339:494

37. Omohundro J, Elderbrook M, Ringer T (1992) Laryngospasm after administration of gadopentetate dimeglumine. J Magn Reson Imaging 1:729-730

38. Chan C, Bosanko C, Wang A (1989) Pruritis and paraesthesia after IV adminstration of Gd-DTPA. Am J Neuroradiol 10:\$53

39. McAlister V, Kissane J (1990) The effect of Gd-dimeglumine on subcutaneous tissues: a study with rats. Am J Neuroradiol 11:325-327

40. Cohan R, Elder RA, z et al (1991) Extravascular toxicity of two magnetic resonance contrast agents: preliminary experience in the rat. Invest Radiol 26:224-226

41. Kanal E, Applegate G, Gillen C (1990) Review of adverse reactions, including anaphylaxis, in 5260 cases receiving Gadolinium-DTPA by bolus injection. Radiology $177(\mathrm{P}): 159$

42. Harbury O (1991) Generalized seizure after IV gadopentetate dimeglumine. Am J Neuroradiol 12:666

43. Harpur E, Worah D, Halls P, Holtz E, Furuhama K, Nomura H (1993) Preclinical safety assessment and pharmacokinetics of gadodiamide injection, a new magnetic resonance imaging contrast agent. Invest Radiol 28:S280

44. Elster AD (1994) Questions and answers in magnetic resonance imaging. Mosby Year Book, St Louis

45. Hadford DJ, Orrison WW Jr, Stimac GK, Kelsey CA (1989) Ultra low-field gd-DTPA-enhanced MR imaging: dosage and administration. Radiology 173 (P):255

46. Freiherr G, Stephenson GM (1990) Indifference to safety heightens MR risks. Diagn Imaging 12 (6):79-83

47. Bieze J (1992) Careful patient screening crucial to MRI safety. Diagn Imaging 57/58:63

48. FDA receives reports of burns caused by MRI scanning units (1992) Radiol Today 9:1

49. Klucznik RP, Carrier DA, Pyka R, Haid RW (1993) Placement of a ferromagnetic intracerebral aneurysm clip in a magnetic field with a fatal outcome. Radiology 187:855-856

50. Kelley W, Paglen PG, Pearson JA, San Diego AG, Soloman MA (1986) Ferromagnetism of intraocular foreign body causes unilateral blindness after MR study. AJNR 7:234-245 
51. FDA Magnetic resonance diagnostic device (1988) Panel recommendation and report on petitions for MR reclassification. Fed Reg 53:7575-7579

52. Sheldon P, Kaufman L, Carlson J (1991) Forces and torques produced by a $640-$ Gauss permanent magnet on ferromagnetic objects. J Neuroimaging 1:184-190

53. Shellock FG, Crues JV (1988) MRI: safety considerations in magnetic resonance imaging. MRI 2:25-30

54. Shellock FG (1989) Biological effects and safety aspects of magnetic resonance imaging. Magn Reson Q 5:243261

55. Kanal E, Talagala L, Shellock FG (1990) Safety considerations in MR imaging. Radiology 176:593-606

56. Lund G, Nelson JD, Wirtschafter JD et al (1986) Tatooing of eyelids: magnetic imaging artifacts. Opthamic Surg 17:550-553

57. Sacco DA, Steiger DA, Bellon EM et al (1987) Artifacts caused by cosmetics in MR imaging of the head. Am J Roentgenol 148:1001-1004

58. Jackson JG, Acker JD (1987) Permanent eyeliner and MR imaging. Am J Roentgenol 149:1080

59. Pusey E, Lufkin RB, Brown RKJ et al (1986) Magnetic resonance imaging artifacts: mechanism and clinical significance. Radiographics 6:891-911

60. Kelly WM, Pagle PG, Pearson A et al (1986) Ferromagnetism of intraocular foreign body causes unilateral blindness after MR study. Am J Neuroradiol 7:243-245

61. Shellock FG, Kanal E (1991) Policies, guidelines, and recommendations for MR imaging safety and patient management. J Magn Reson Imaging 1:97-101

62. Kelsey CA, King JN, Keck GM, Chiu MT et al (1991) Ocular hazard of metallic fragments during MR imaging at $0.064 \mathrm{~T}$. Radiology 180:282-283

63. Hayes DL, Holmes DR, Gray JE (1987) Effect of a 1.5 tesla nuclear magnetic resonance imaging scanner on implanted permanent pacemakers. J Am Coll Cardiol 10:782-786

64. Erlebacher JA, Cahill PT, Pannizzo F, Knowles JR (1986) Effect of magnetic resonance imaging on DDD pacemakers. Am J Cardiol 57:437-440

65. Kanal E, Shellock F (1993) MR imaging of patients with intracranial aneurysm clips. Radiology 187:612614

66. Kanal E, Shellock F (1994) The value of published data regarding MR compatibility of metallic implants and devices. Am J Neuroradiol 15:1394-1396

67. Flaherty JA, Hoskinson K (1989) Emotional distress during magnetic resonance imaging. $\mathrm{N}$ Engl J Med 320:467-468

68. Fishbain DA, Goldberg M, Labbe E et al (1988) Longterm claustrophobia following magnetic resonance imaging. Am J Psychiatry 145:1038-1039

69. Quirk ME, Letendre AJ, Ciottone RA et al (1989) Anxiety in patients undergoing MR imaging. Radiology 170:463-466

70. Quirk ME, Letendre AJ, Ciottone RA et al (1989) Evaluation of three psychological interventions to reduce anxiety during MR imaging. Radiology 173:759-762

71. Hricak H, Amparo EG (1984) Body MRI: alleviation of claustrophobia by prone positioning. Radiology 152:819

72. Weinreb JC, Maravilla KR, Peshock R et al (1984) Magnetic resonance imaging: improving patient tolerance and safety. Am J Roentgenol 143:1285-1287

73. Klonoff EA, Janata JW, Kaufman B (1986) The use of systematic desensitization to overcome resistance to magnetic resonance imaging (MRI) scanning. J Behav Ther Exp Psychiatry 17:189-192

74. Granet RB, Belber LJ (1990) Claustrophobia during MR imaging. N J Med 87 (6):479-482

75. Phelps LA (1990) MRI and claustrophobia. Am Fam Physician 42 (4):930

76. Woodward P, Orrison WW Jr (1997) MRI optimization: a hands-on approach. McGraw Hill, New York
77. Orrison WW Jr, Sanders JA (1995) Clinical brain imaging: computerized axial tomography and magnetic resonance imaging. In: Orrison WW, Jr, Lewine JD, Sanders JA, Hartshorne MF (eds) Functional brain imaging. Mosby Year Book, St Louis, pp 97-144

78. Haughton VM, Rimm AA, Sobocinski KA et al (1986) A blinded clinical comparison of MR imaging and CT in neuroradiology. Radiology 160:751-755

79. Osborn AG (1994) Infections of the brain and its linings. In: Osborn AG (ed) Diagnostic neuroradiology, Mosby-Year Book, Inc., St. Louis, MO, pp 673-712

80. Barkovich AJ (1990) Infections of the nervous system. In: Barkovich AJ (ed) Pediatric neuroimaging. Raven, New York, pp 293-325

81. Chang KH, Han MH, Roh JK et al (1990) Gd-DTPAenhanced MR imaging of the brain in patients with meningitis: comparison with CT. AJNR 11:69-76

82. Chang KH, Han M-H, Roh J-K et al (1991) Gd-DTPA enhanced MR imaging in intracranial tuberculosis. Neuroradiology 238:340-344

83. Matthews VP, Kuharik MA, Edwards MK et al (1988) Gd-DTPA enhanced MR imaging of experimental meningitis: evaluation and comparison with CT. AJNR 9:1045-1050

84. Offenbacher H, Fazekas F, Schmidt R et al (1991) MRI in tuberculosis meningoencephalitis: report of four cases and review of the neuroimaging literature. Neurol 238:340-344

85. Zimmerman RD, Weingarten K (1991) Neuroimaging of cerebral abscesses. Neuroimaging Clin North Am $1: 1-16$

86. Okagaki H (1989) Fundamentals of neuropathology, 2nd edn. Igaku-Shoin, New York

87. Haimes AB, Zimmerman RD, Morgello $S$ et al (1989) MR imaging of brain abscesses. AJNR 10:279-291

88. Barloon TJ, Yuh WTC, Knepper LE et al (1990) Cerebral ventriculitis: MR findings $\mathrm{J}$ Comput Assist Tomogr 14:272-275

89. Bazan C III, Rinaldi MG, Rauch RR, Jinkins JR (1991) Fungal infections of the brain. Neuroimaging Clin North Am 1:57-88

90. Bowen BC, Post MJD (1991) Intracranial infection. In: Atlas SW (ed) Magnetic resonance imaging of the brain and spine. Raven, New York, pp 501-538

91. Zee C-S, Segall HD, Boswell W et al (1988) MR imaging of neurocysticercosis. J Comput Assist Tomogr 12:927-934

92. Chang KH, Cho SY, Hesselink JR et al (1991) Parasitic diseases of the central nervous system. Neuroimaging Clin North Am 1:159-178

93. Tsai M-D, Chang C-N, Ho Y-S et al (1993) Cerebral sparganosis diagnosed and treated with stereotactic techniques. J Neurosurg 78:129-132

94. Lane JI, Flanders AE, Doan HT, Bell RD (1991) Assessment of carotid artery patency in routine spinecho MR imaging of the brain. AJNR 12:819-826

95. Osborn AG (1994) Stroke. In: Osborn AG (ed) Diagnostic neuroradiology. Mosby-Year Book, Inc., St. Louis, MO, pp 330-338

96. terPenning B (1992) Pathophysiology of stroke. Neuroimaging Clin North Am 2:389-408

97. Bryan RN (1990) Imaging of acute stroke. Radiology $177: 615-616$

98. Shuaib A, Lee D, Pelz D et al (1992) The impact of magnetic resonance imaging on the management of acute ischemic stroke. Neurology 42:816-818

99. Bryan RN, Levy LM, Whitlow WD et al (1991) Diagnosis of acute cerebral infarction: comparison of CT and MR imaging, AJNR 12:611-620

100. Mueller DP, Yuh WTC, Fisher DJ et al (1993) Arterial enhancement in acute cerebral ischemia: clinical and angiographic correlation. AJNR 14:661-668 
101. Elster AD, Moody DM (1990) Early cerebral infarction: gadopentetate dimeglumine enhancement. Radiology 177:627-632

102. Yuh WTC, Crain MR, Loes DJ et al (1991) MR imaging of cerebral ischemia: findings in the first 24 hours. AJNR 12:621-629

103. Alberts MJ, Faulstich ME, Gray L (1992) Stroke with negative brain magnetic resonance imaging. Stroke 23:663-667

104. Elster AD (1992) Enhancement patterns in cerebral infarction. MRI 30-33

105. Asato R, Okumaura R, Konishi J (1991) "Fogging effect" in MR of cerebral infarct. J Comput Assist Tomogr 15:160-162

106. Parisi J, Place C, Nag S (1988) Calcification in a recent cerebral infarct: radiologic and pathologic correlation. Can J Neurol Sci 15:192-195

107. Lundblom N, Katevuo K, Kumo M et al (1992) T1 in subacute and chronic brain infarctions: time-dependent development. Invest Radiol 27:673-680

108. Kuhn MJ, Mikulis DJ, Ayoub DM et al (1989) Wallerian degeneration after cerebral infarction: evaluation with sequential MR imaging. Radiology 172:170-182

109. Boyko OB, Burger PC, Shelburne JD, Ingram P (1992) Non-heme mechanisms for T1 shortening: pathologic, CT, and MR elucidation. AJNR 13:1439-1445

110. Regli L, Regli F, Maeder P, Bogousslavski J (1993) Magnetic resonance imaging with gadolinium contrast in small deep (lacunar) cerebral infarcts. Arch Neurol 50:175-180

111. Orrison WW Jr, Gentry LR, Stimac GK, Tarrel RM, Espinosa MC, Cobb LC (1994) Blinded comparison of cranial CT and MR in closed head injury evaluation. AJNR Am J Neuroradiol 15:351-356

112. Zimmerman RA, Bilaniuk LT, Hackney DB, Goldberg HI, Grossman RI (1986) Head injury: early results comparing CT and high-field MR. AJNR Am J Neuroradiol 7:757-764

113. Gentry LR, Godersky JC, Thompson BH (1989) Traumatic brain stem injury: MR imaging. Radiology 171:177-187

114. Gentry LR, Godersky JC, Thompson BH (1988) MR imaging of head trauma: review of the distribution and radiopathologic features of traumatic lesions. AJNR Am J Neuroradial 9:101-110

115. Gentry LR, Godersky JC, Thompson B, Dunn VD (1988) Prospective comparative study of intermediatefield MR and CT in the evaluation of closed head trauma. AJNR Am J Neuroradiol 9:91-100

116. Han IS, Kaufman B, Alfidi RJ et al (1984) Head trauma evaluated by magnetic resonance and computed tomography: a comparison. Radiology 150:71-77

117. Hesselink JR, Dowd CF, Healy ME, Hajek P, Baker LL, Luerssen TG (1988) MR imaging of brain contusions: a comparative study with CT. AJNR Am J Neuroradiol 9:269-278

118. Gentry LR, Thompson B, Godersky JC (1988) Trauma to the corpus callosum: MR features. AJNR Am J Neuroradiol 9:1129-1138

119. Moon KL Jr, Brant-Zawadzki M, Pitts LH, Mills CM (1984) Nuclear magnetic resonance imaging of CTisodense subdural hematomas. AJNR Am J Neuroradiol 5:319-322

120. Levin HS, Handel SF, Goldman AM, Eisenberg HM, Guinto FC (1985) Magnetic resonance imaging after "diffuse" nonmissile head injury. Arch Neurol 42:963968

121. Langfitt TW, Obrist WD, Alavi A et al (1986) Computerized tomography, magnetic resonance imaging, and positron emission tomography in the study of brain trauma: preliminary observations. J Neurosurg $64: 760-767$
122. Gandy SE, Snow RB, Zimmerman RD, Deck MDF (1984) Cranial nuclear magnetic resonance imaging in head trauma. Ann Neurol 16:254-257

123. Snow RB, Zimmerman RD, Gandy SE, Deck MDF (1986) Comparison of magnetic resonance imaging and computed tomography in the evaluation of head injury. Neurosurgery 18:45-52

124. Jenkins A, Teasdale G, Hadley MDM, MacPherson P, Rowan JO (1986) Brain lesions detected by magnetic resonance imaging in mild and severe head injuries. Lancet 2:445-446

125. French BN, Dublin AB (1977) The value of computerized tomography in the management of 1000 consecutive head injuries. Surg Neurol 7:171-183

126. Zimmerman RD, Danziger A (1982) Extracerebral trauma. Radiol Clin North Am 20:105-121

127. Moseley IF, Zilkha E (1976) The role of computerized axial tomography (EMI-scanning) in the diagnosis and management of cranio-cerebral trauma. J Neuroradiol 3:277-296

128. Bricolo AP, Pasut LM (1984) Extradural hematoma: toward zero mortality. Neurosurgery 14:8-12

129. Seelig JM, Becker DP, Miller JD, Greenberg RP, Ward JD, Choi SC (1981) Traumatic acute subdural hematoma: major mortality reduction in comatose patients treated within four hours. N Engl J Med 304:15111518

130. Adams JF, Genneralli TA, Graham DI (1982) Brain damage in non-missile head injury observations in man and subhuman primates. In: Smith WT, Cavanagh JB (eds) Recent advances in neuropathology, vol 2. Churchill Livingstone, Edinburgh, pp 165-190

131. Adams JH, Graham DI, Scott G, Parker LS, Doyle D (1980) Brain damage in fatal non-missile head injury. J Clin Pathol 33:1132-1145

132. Cooper PR, Maravilla K, Kirkpatrick J et al (1979) Traumatically induced brain stem hemorrhage and the computerized tomographic scan: clinical pathological, and experimental observations. Neurosurgery $4: 115-124$

133. Baker SP (1989) Injury science comes of age (editorial). JAMA 262:2284-2285

134. Yoon HC, Lufkin RB, Vinuela F, Bentson J, Martin N, Wilson G (1988) MR of acute subarachnoid hemorrhage. AJNR Am J Neuroradiol 9:404-405

135. Janousek A (1991) Head injuries: three years experience with ultra-low-field MRI. Neuroradiology 33 [Suppl]:616-617

136. Chaney RK, Taber KH, Orrison WW, Hayman LA (1992) Magnetic resonance imaging of intracerebral hemorrhage at different field strengths. Neuroimaging Clin North Am 2:25-51

137. Atlas SW, Grossman RI, Gomori JM et al (1987) Hemorrhagic intracranial malignant neoplasms: spin-echo MR imaging. Radiology 164:71-77

138. Osborn AG (1994) Acquired metabolic, white matter and degenerative diseases of the brain. In: Osborn AG (ed) Diagnostic neuroradiology. Mosby-Year Book, Inc., St. Louis, MO, pp 748-778

139. Escourolle R, Poirier J (1973) Pathology of the central nervous system; demyelinating diseases. Manual of basic neuropathology. Saunders, Philadelphia, pp 128135

140. Merritt HH, Moses HL, Moses L (1979) A textbook of neurology; diseases of the myelin sheath, 6th edn. Lea and Febiger, Philadelphia, pp 767-824

141. Adams RD, Victor M (1981) Principles of neurology; multiple sclerosis and allied demyelinative diseases. McGraw-Hill, New York, pp 647-663

142. Mendes JH, Kinsbourne M, Batzdorf U, Gabriel RS, Weil ML (1974) Textbook of child neurology; heredodegenerative diseases. Lea and Febiger, Philadelphia, pp 101-113 
143. Holland BA (1987) Diseases of white matter. Magnetic resonance imaging of the central nervous system. $\mathrm{Ra}$ ven, New York, pp 259-278

144. Barkovich AJ (1987) Pediatric neuroimaging; metabolic and destructive brain disorders. Raven, New York, pp 259-278

145. Leestma JE (1988) Forensic neuropathology. Raven, New York, pp 137-156

146. Edwards MK, Bonnin JM (1991) White matter diseases. In: Atlas SW (ed) Magnetic resonance imaging of the brain and spine. Raven, New York, pp 467-500

147. Merrill JE, Graves MC, Mulder DG (1992) Autoimmune disease and the nervous system: biochemical, molecular, and clinical update. West J Med 156:639646

148. Tienari PJ, Salonen O, Wikstrom J et al (1992) Familial multiple sclerosis: MRI findings in clinically af fected and unaffected siblings. J Neurol Neurosurg Psychiatr 55:883-886

149. Niebler G, Harris T, Davis T, Raos K (1992) Fulminant multiple sclerosis. AJNR 13:1547-1551

150. Kepes JJ (1993) Large focal tumor-like demyelinating lesions of the brain: intermediate entity between multiple sclerosis and acute disseminated encephalomyelitis. A study of 31 patients. Ann Neurol 33:18-27

151. Lee KH, Hashimoto SA, Hooge JP et al (1991) Magnetic resonance imaging of the head in the diagnosis of multiple sclerosis: a prospective 2-year follow-up with comparison of clinical evaluation, evoked potentials, oligoclonal banding, and CT. Neurology 41:657660

152. Barkhof F, Scheltens P, Frequin STFM et al (1992) Relapsing-remitting multiple sclerosis: sequential enhanced MR imaging vs. clinical findings in determining disease activity. AJR 159:1041-1047

153. Capra R, Marciano N, Vignolo LA et al (1992) Gadolinium-pentetic acid magnetic resonance imaging in patients with relapsing remitting multiple sclerosis. Arch Neurol 49:687-689

154. Runge VM (1992) MRI of multiple sclerosis in the brain. MRI 2-10

155. Yetkin FZ, Haughton VM (1992) Common and uncommon manifestations of MS on MRI. MRI 13-18

156. Powell T, Sussman JG, Davies-Jones GAB (1992) MR imaging in acute multiple sclerosis: ring-like appearance in plaques suggesting the presence of paramagnetic free radicals. AJNR 13:1544-1546

157. Giang DW, Poduri KR, Eskin TA et al (1992) Multiple sclerosis masquerading as a mass lesion. Neuroradiology $34: 150-154$

158. Zagzag D, Miller DC, Kleinman GM et al (1993) Demyelinating disease versus tumor in surgical neuropathology. Am J Surg Pathol 17:537-545

159. Miller DH, MacManus DG, Bartlett PA et al (1993) Detection of optic nerve lesions in optic neuritis using frequency-selective fat-saturation sequences. Neuroradiology 35:156-158

160. Osborn AG (1990) MRI of the sellar/juxtasellar region. I. Intrasellar and suprasellar masses. MRI 19-30

161. Osborn AG (1991) Handbook of neuroradiology. Mosby Year Book, St Louis, pp 331-343

162. Naidich TP, Pinto RS, Kushner MJ, Lin JP, Kricheff II, Leeds NE, Chase NE (1976) Evaluation of sellar and parasellar masses by computed tomography. Radiology 120:91-99

163. Zimmerman RA (1990) Imaging of the intrasellar, suprasellar, and parasellar tumors. Semin Roentgenol 25:174-197

164. Sakamoto Y, Takahashi M, Korogi Y, Bussaka H, Ushio Y (1991) Normal and abnormal pituitary glands: gadopentetate dimeglumine-enhanced MR imaging. Radiology 178:441-445

165. Patel SC, Sanders WP (1990) MRI of the pituitary gland: adenomas. MRI 12-20
166. Tindall GT, Barrow DL (1986) Pathology of the pituitary gland. Disorders of the pituitary. Mosby, St Louis, pp 203-229

167. Johnson DE, Woodruff WW, Allen IS, Cera PJ, Funkhouser GR, Coleman LL (1991) MR imaging of the sellar and juxtasellar regions. Radiographics 11:727758

168. Bonneville JF, Cattin F, Moussa-Bacha K, Portha C et al (1983) Dynamic computed tomography of the pituitary gland: the "Tuft sign." Radiology 149:145-148

169. Orrison WW Jr, Watridge CB, Gabatin AR, Pretorius HT, Floyd JP III et al (1983) Dynamic computed tomographic scanning of the pituitary gland. Radiology 149 (P):262

170. Tien RD, Kucharczyk J, Bessette J, Middleton M (1992) MR imaging of the pituitary gland in infants and children: changes in size, shape, and MR signal with growth and development. AJR 158:1151-1154

171. Elster AD, Chen MY, Williams DW, Key LL (1990) Pituitary gland: MR imaging of physiologic hypertrophy in adolescence. Radiology 174:681-685

172. Tindall GT, Barrow DL (1986) Acromegaly. Disorders of the pituitary. Mosby, St Louis, pp 203-229

173. Pusey E, Kortman KE, Flannigan BD, Tsuruda J, Bradley WG (1987) MR characterization. AJNR 8:439-444

174. Bradley WG Jr, Waluch V, Yadley RA, Wycoff RR (1984) Comparison of CT and MR in 400 patients with suspected disease of the brain and cervical spinal cord. Radiology 152:695-702

175. Chen CN, Sank VJ, Cohen SM, Hoult DI (1986) The field dependence of NMR imaging. I. Laboratory assessment of signal-to-noise ration and power deposition. Magn Reson Med 3:722-729

176. Loult DI, Chen CN, Sank VJ (1986) The field dependence on NMR imaging. II. Arguments concerning an optimal field strength. Magn Reson Med 3:730-746

177. A special issue on MRI (1988) Health Technol 2:20-23

178. Kaufman L, Crooks LE (1987) Field strength issues in MRI. Adm Radiol 6:17-19

179. Orrison WW Jr, Stimac GK, Stevens EA, LaMasters DL et al (1991) Comparison of CT, low-field-strength MR imaging and high-field-strength MR imaging. Work in progress. Radiology 181:121-127

180. Kent LD, Larson EB (1988) Magnetic resonance imaging of the brain and spine. Ann Intern Med 108:402424

181. Gentry LR, Godersky JC, Thompson B, Dunn VD (1988) Prospective comparative study of intermediatefield MR and CT in the evaluation of closed head trauma. AJR 150:673-682

182. Hirsch WL Jr, Hryshko FG, Sekhar LN et al (1988) Comparison of MR imaging, CT, and angiography in the evaluation of the enlarged cavernous sinus. AJNR 9:907-915

183. Bradley WG Jr, Waluch V, Yadley RA, Wycoff RR (1984) Comparison of CT and MR in 400 patients with suspected disease of the brain and cervical spinal cord. Radiology 152:695-702

184. Brant-Zawadzki M, Davis PL, Crooks LE et al (1983) NMR demonstration of cerebral abnormalities: comparison with CT. AJNR 4:117-124

185. Han JS, Kaufman B, Alfidi RJ et al (1995) Head trauma evaluated by magnetic resonance and computed tomography: a comparison. Radiology 150:71-77

186. Hesselink JR, Dowd CF, Healy ME, Hajek P, Baker LL, Luerssen TG (1988) MR imaging of brain contusions: a comparative study with CT. AJNR 9:269-278

187. Jacobs L, Kinkel WR, Polachini I, Kinkel RP (1986) Correlations of nuclear magnetic resonance imaging, computerized tomography, and clinical profiles in multiple sclerosis. Neurology 36:27-34

188. Haughton VM, Rimm AA, Sobocinski KA et al (1986) A blinded clinical comparison of MR imaging and CT in neuroradiology. Radiology 160:751-755 
189. Norman D (1987) Vascular disease: hemorrhage. In: Brant-Zawadski M, Norman D et al (eds) Magnetic resonance imaging of the central nervous system. Raven, New York, pp 209-220

190. Beers GJ, Raque GH, Wagner GG, Shields CB, Nichols GR II, Johnson JR, Meyer JE (1988) MR imaging in acute cervical spine trauma. J Comput Assist Tomogr 12 (5):755-761

191. Kerslake RW, Jaspan T, Worthington BS (1991) Magnetic resonance imaging of spine trauma. $\mathrm{Br} J$ Radiol 64:386-402

192. Kulkarni MV, McArdle CB, Kopanicky D, Miner M, Cotler HB, Lee KF, Harris JH (1987) Acute spinal cord injury: MR imaging at 1.5 T. Radiology 164:837-843

193. Mirvis SE, Geisler FH, Jelinek JJ, Joslyn JN, Gellad F (1988) Acute cervical spine trauma: evaluation with 1.5 T MR imaging. Radiology 166:807-816

194. Tarr RW, Drolshagen LF, Kerner TC, Allen JH, Partain CL, James AE Jr (1987) MR imaging of recent spinal trauma. J Comput Assist Tomogr 11 (3):412-417

195. Seeger LL (1989) The shoulder. In: Bassett LW, Gold RH, Seeger LL (eds) MRI atlas of the musculoskeletal system. Deutscher Ärzte Verlag, Cologne, pp 95-128 